\title{
Rethinking the global secondary organic aerosol (SOA) budget: stronger production, faster removal, shorter lifetime
}

\author{
Alma Hodzic ${ }^{1}$, Prasad S. Kasibhatla ${ }^{2}$, Duseong S. Jo ${ }^{3}$, Christopher D. Cappa ${ }^{4}$, Jose L. Jimenez ${ }^{5}$, Sasha Madronich ${ }^{1}$, \\ and Rokjin J. Park ${ }^{3}$ \\ ${ }^{1}$ National Center for Atmospheric Research, Boulder, CO, USA \\ ${ }^{2}$ Nicholas School of the Environment, Duke University, Durham, USA \\ ${ }^{3}$ School of Earth and Environmental Science, Seoul National University, Seoul, Republic of Korea \\ ${ }^{4}$ Department of Civil and Environmental Engineering, University of California, Davis, CA, USA \\ ${ }^{5}$ Department of Chemistry and Biochemistry, University of Colorado, Boulder, CO, USA \\ Correspondence to: Alma Hodzic (alma@ucar.edu)
}

Received: 17 October 2015 - Published in Atmos. Chem. Phys. Discuss.: 18 November 2015

Revised: 28 March 2016 - Accepted: 30 May 2016 - Published: 29 June 2016

\begin{abstract}
Recent laboratory studies suggest that secondary organic aerosol (SOA) formation rates are higher than assumed in current models. There is also evidence that SOA removal by dry and wet deposition occurs more efficiently than some current models suggest and that photolysis and heterogeneous oxidation may be important (but currently ignored) SOA sinks. Here, we have updated the global GEOSChem model to include this new information on formation (i.e., wall-corrected yields and emissions of semi-volatile and intermediate volatility organic compounds) and on removal processes (photolysis and heterogeneous oxidation). We compare simulated SOA from various model configurations against ground, aircraft and satellite measurements to assess the extent to which these improved representations of SOA formation and removal processes are consistent with observed characteristics of the SOA distribution. The updated model presents a more dynamic picture of the life cycle of atmospheric SOA, with production rates 3.9 times higher and sinks a factor of 3.6 more efficient than in the base model. In particular, the updated model predicts larger SOA concentrations in the boundary layer and lower concentrations in the upper troposphere, leading to better agreement with surface and aircraft measurements of organic aerosol compared to the base model. Our analysis thus suggests that the long-standing discrepancy in model predictions of the vertical SOA distribution can now be resolved, at least in part, by a stronger source and stronger sinks leading to a shorter lifetime. The predicted global SOA burden in the updated model
\end{abstract}

is $0.88 \mathrm{Tg}$ and the corresponding direct radiative effect at top of the atmosphere is $-0.33 \mathrm{~W} \mathrm{~m}^{-2}$, which is comparable to recent model estimates constrained by observations. The updated model predicts a population-weighed global mean surface SOA concentration that is a factor of 2 higher than in the base model, suggesting the need for a reanalysis of the contribution of SOA to PM pollution-related human health effects. The potential importance of our estimates highlights the need for more extensive field and laboratory studies focused on characterizing organic aerosol removal mechanisms and rates.

\section{Introduction}

Secondary organic aerosol (SOA) is formed through complex photochemical gas and aqueous reactions involving a variety of biogenic and anthropogenic hydrocarbons, and it accounts for a substantial fraction of the submicron aerosol mass (Zhang et al., 2007). Despite its importance from a climate and air quality perspective, there are significant uncertainties in our understanding of SOA. A recent intercomparison study of more than 20 state-of-the-art global aerosol models showed that estimates of the SOA annual production rate vary among models by an order of magnitude, from $\sim 13$ to $119 \mathrm{Tg} \mathrm{yr}^{-1}$, and estimates of its lifetime range from 5 to 15 days (Tsigaridis et al., 2014). This wide spread in model results arises from a limited knowledge of underlying pro- 
cesses controlling both SOA formation and removal in the atmosphere.

SOA formation rates used in current large-scale models are commonly based on yields derived from chamber experiments, which might be severely underpredicted (up to a factor of 4) due to loses of organic vapors onto chamber walls (La et al., 2016; Zhang et al., 2014; Matsunaga and Ziemann, 2010). As a consequence, these models often significantly underpredict ambient SOA concentrations (e.g., Heald et al., 2011; Spracklen et al., 2011). To compensate for these model underestimations in an effort to match surface organic aerosol (OA) and SOA measurements, models increasingly include unconstrained aging parameterizations in which more volatile organic constituents are converted to less volatile ones (e.g., Jo et al., 2013; Shrivastava et al., 2011; Tsimpidi et al., 2010). A detailed analysis by Heald et al. (2011) suggests, however, that an adjustment of this sort will lead to other biases in model performance. In their study, global model simulations that were adjusted to correctly reproduce surface concentrations of OA displayed unrealistic accumulation of OA in the upper troposphere. These studies suggest that in addition to SOA formation processes, there is also a need to re-examine the representation of SOA removal processes in chemistry-climate models.

Wet scavenging is typically the major direct loss $(90 \%)$ of SOA in global models (Tsigaridis et al., 2014), with dry deposition representing a much smaller sink $(<10 \%)$ due to the small dry deposition velocities predicted for accumulation mode aerosols (Seinfeld and Pandis, 2006; Farmer et al., 2013). SOA loss can also occur indirectly by wet and dry removal of gas-phase semi-volatile oxidized species, which act to suppress the amount of condensable material available for SOA formation through gas-particle partitioning. Global models typically treat the removal of these gas-phase oxidized volatile organic compounds (OVOCs) in an ad hoc manner using constant Henry's law solubility coefficients between $10^{3}$ and $10^{6} \mathrm{M} \mathrm{atm}^{-1}$ (Knote et al., 2015, and references therein). However, recent explicit modeling results (Hodzic et al., 2014) show that Henry's law solubility coefficients can vary significantly as a function of the volatility of OVOCs, indicating the need for a reassessment of effective wet and dry removal lifetimes of SOA.

In addition to wet and dry removal, there is increasing evidence of other potentially important SOA loss mechanisms that are, to our knowledge, rarely implemented in global model calculations. Laboratory studies suggest that photolytic processing of organic gases and particles can remove tropospheric aerosols on timescales comparable to those of wet deposition, although the chemical transformations involved are not well understood (Henry and Donahue, 2012; Epstein et al., 2014; Wong et al., 2014). Model estimates performed by Hodzic et al. (2015) indicate that SOA photolytic frequencies equivalent to $0.04 \%$ of typical $\mathrm{NO}_{2}$ photolysis frequencies can decrease SOA tropospheric concentrations by $20-60 \%$. Furthermore, organic compounds at or near the surface of particles were also found to be sensitive to heterogeneous (surface) oxidation by $\mathrm{OH}$ and $\mathrm{O}_{3}$ (Moise and Rudich, 2002; Molina et al., 2004; Kroll et al., 2009; George and Abbatt, 2010; Ortega et al., 2015). An attempt to include this process in a global model by oxidizing SOA with $\mathrm{OH}$ with an effective gas-phase-equivalent rate constant of $10^{-12} \mathrm{~cm}^{3}$ molecule ${ }^{-1} \mathrm{~s}^{-1}$ and assuming that only $5 \%$ of reacted molecules is lost, suggested a $25 \%$ loss of SOA in the upper troposphere and $15 \%$ elsewhere (Heald et al., 2011). The implications of $\mathrm{O}_{3}$ oxidation on the large-scale SOA distribution have not yet been estimated using 3-D models. Given the potential effect of these processes on SOA life cycle, there is a need to estimate the relative efficiency of SOA removal by these competing pathways in a common modeling framework.

In this study, we focus on re-assessing the global SOA distribution, budget and radiative forcing in light of new insights into SOA production and loss processes in the atmosphere derived from recent laboratory measurements and theoretical calculations. We perform a series of model sensitivity simulations using the GEOS-Chem global model to evaluate the importance of the wall-corrected SOA yields, the additional emissions of semi-volatile (SVOC) and intermediate (IVOC) volatility organic species, as well as the effect of additional removal pathways discussed above on the SOA spatial distribution and budget. We then compare simulated SOA from these sensitivity runs against a suite of surface and free-tropospheric measurements to investigate whether the updated treatment of sources and sinks leads to a more realistic simulation of observed spatial SOA patterns.

\section{Modeling approach}

In this study, we use the GEOS-Chem global chemical transport model (Bey et al., 2001; http://acmg.seas.harvard.edu/ geos/index.html) at a horizontal resolution of $2^{\circ} \times 2.5^{\circ}$ with 47 vertical hybrid sigma-pressure levels up to $0.01 \mathrm{hPa}$ to conduct simulations of aerosol-oxidant chemistry for 20052008 with a spin-up of 1 year (2004). The model uses assimilated meteorological data from the Goddard Earth Observing System (GEOS-5) of the NASA Global Modeling and Assimilation Office (GMAO). The standard version of GEOSChem includes a comprehensive description of tropospheric $\mathrm{NO}_{x}$-hydrocarbon- $\mathrm{O}_{3}$ gas-phase chemistry, as well as the treatment of major aerosol components including sulfate, nitrate, ammonium, black carbon, and primary organic aerosols (POA). Anthropogenic volatile organic compound (VOC) emissions are taken from the REanalysis of the TROpospheric chemical composition (RETRO) inventory, whereas POA emissions are from Bond et al. (2007). Biomass burning emissions for all species are based on the Global Fire Emission Database version 3 (GFEDv3) inventory. Biogenic emissions are calculated online using the MEGAN v2.1 model (Guenther et al., 2012). Here, we use v.9.1.2 of the model 
with an added extension for SOA that incorporates a volatility basis set (VBS) approach as described in Jo et al. (2013). This base SOA model configuration is described in Sect. 2.1. We have implemented specific updates to account for wallcorrected SOA yields, SOA formation from additional longchain n-alkanes, solubility of organic vapors, and heterogeneous and photolytic loss of SOA, as described in Sects. 2.2 and 2.3.

\subsection{Base SOA model configuration}

The base version of GEOS-Chem uses the VBS approach (hereafter referred as VBS_REF) to simulate SOA as previously described in Jo et al. (2013). In this approach, oxygenated semi-volatile organic compounds formed by the gas-phase reaction of hydrocarbon species such as isoprene, monoterpenes, sesquiterpenes and aromatic compounds, with $\mathrm{OH}, \mathrm{O}_{3}$ and $\mathrm{NO}_{3}$, are allocated to four volatility bins with saturation concentrations $\left(C^{*}\right)$ of 1,10 and 100 to $1000 \mu \mathrm{g} \mathrm{m}^{-3}$ at $300 \mathrm{~K}$. Two additional volatility bins 0.01 and $0.1 \mu \mathrm{g} \mathrm{m}^{-3}$ are used to represent SOA formed from aged anthropogenic precursors by further reactions of OVOCs with $\mathrm{OH}$. Partitioning between gas and particle phase in each bin in each model grid cell is calculated based on the total OA concentration and temperature in the grid cell. The temperature dependence of the partitioning coefficient is calculated based on an assumed value for the enthalpy of vaporization of $112 \mathrm{~kJ} \mathrm{~mol}^{-1}$ at $C^{*}=0.01 \mu \mathrm{g} \mathrm{m}^{-3}$ with a decrease of $6 \mathrm{~kJ} \mathrm{~mol}^{-1}$ for each increase in order of magnitude of $C^{*}$ (Robinson et al., 2007). Chemical aging of anthropogenic oxidation intermediates with $\mathrm{OH}$ is considered with a rate constant of $4 \times 10^{-11} \mathrm{~cm}^{3}$ molecule $\mathrm{e}^{-1} \mathrm{~s}^{-1}$ and leads to a reduction of the vapor pressure of the products by 1 order of magnitude. There was no mass increase (oxygen gain) upon aging reaction. Biogenic precursors are not artificially aged. It should be noted that we do not support in any case the ad hoc aging of oxidation products, but since this is a common modeling practice (e.g., Tsimpidi et al., 2010; Jo et al., 2013) we use it in this study as a basis for comparisons with our updated model described below.

\subsection{Updated parameterization of SOA formation}

We have updated the SOA formation mechanism to use a modified set of VBS product yields (hereafter referred to as VBS_NEW) for which the influence of vapor wall losses on the SOA yields in chamber studies have been, at least approximately, accounted for. Specifically, synthetic SOA yield curves (i.e., the amount of SOA formed vs. the amount of VOC reacted) were generated using the Statistical Oxidation Model (SOM) based on previously derived fits to chamber data (Cappa and Wilson, 2012). The SOM accounts for the influence of multi-generational chemistry, including both functionalization and fragmentation. The SOM parameterizations are unique to precursor species and $\mathrm{NO}_{x}$ conditions.
The SOM parameters are determined by fitting laboratory chamber data, specifically the time evolution of the SOA formed during oxidation of a given VOC. All experiments considered were performed in the Caltech chambers and results from the fits are summarized in Zhang et al. (2014). The SOM framework can account for the influence of losses of semi- and low-volatility vapors to the chamber walls on SOA formation (Zhang et al., 2014) using the Matsunaga and Ziemann (2010) methodology. The appropriate value to use for the vapor wall-loss rate coefficient $\left(k_{\text {wall }}\right)$ remains a point of discussion, but can vary between chambers due to differences in chamber size and operation. Here, a value of $k_{\text {wall }}=10^{-4} \mathrm{~s}^{-1}$ was assumed. This is likely a conservative (i.e., low) estimate as Zhang et al. (2014) derived a slightly larger value $\left(2.5 \times 10^{-4} \mathrm{~s}^{-1}\right)$ and Matsunaga and Ziemann (2010) a substantially larger value $\left(\sim 10^{-3} \mathrm{~s}^{-1}\right)$, albeit in the latter case for a different chamber. Here, this conservative estimate is used so as to provide an initial assessment of the influence of vapor wall losses, the effects of which may actually be larger than simulated here if the appropriate $k_{\text {wall }}$ is larger than $10^{-4} \mathrm{~s}^{-1}$ (Cappa et al., 2016). For isoprene specifically, which contains two double bonds and can form products that react as fast, if not faster than, isoprene itself, especially under low- $\mathrm{NO}_{x}$ conditions (Paulot et al., 2009; Surratt et al., 2010; St. Clair et al., 2015), an isoprene-specific version of SOM was also used to fit the chamber observations. Parameterizations resulting from both the original and isoprene-specific SOM formulations have been described and compared in the Supplement (Fig. S1 and Table S2). The primary results in this work are based on the isoprene-specific formulation.

Results from SOM simulations are used to determine parameters for use in the VBS model framework. Specifically, after determining a set of SOM parameters for each precursor with vapor wall losses accounted for, a set of simulations were run for each precursor VOC with: constant $[\mathrm{OH}]=2 \times 10^{6}$ molecules $\mathrm{cm}^{-3}$; run time $=36 \mathrm{~h}$; absorbing seed concentration $=10 \mu \mathrm{g} \mathrm{m}^{-3}$; precursor $[\mathrm{VOC}]=1 \mathrm{ppt}$. The SOM product species from these simulations were then binned by their saturation concentration into logarithmically spaced bins (e.g., $\log C^{*}$ ranging from -2 to 3 , see Table 1 ) according to their gas- plus particle-phase concentrations at the end of the simulation and normalized by the total precursor concentration to determine mass yields as a function of volatility. Thus, the long-time $(36 \mathrm{~h}) \mathrm{VBS}$ mass yields can be calculated as

$a_{\mathrm{VBS}, x}=\frac{\sum_{\log C_{\mathrm{SOM}, i}^{*} \geq x-0.5}^{\log C_{\mathrm{SOM}, i}^{*}<x+0.5} C_{\mathrm{SOM}, i}}{\Delta[\mathrm{HC}]}$,

where $a_{\mathrm{VBS}, x}$ indicates the mass yield in VBS bin $x$ (defined as $\left.x=\log C_{\mathrm{VBS}}^{*}\right), C_{\mathrm{SOM}, i}$ is the gas + particle mass concentration of a given SOM species $i$ after $36 \mathrm{~h}$ of reaction and $C_{\mathrm{SOM}, i}^{*}$ is the saturation concentration of that species, 
Table 1. Parameters used in the new volatility basis set (VBS_NEW). Wall-corrected mass yields are based on the Statistical Oxidation Model (SOM) fit to the chamber data from Zhang et al. (2014). For isoprene, an isoprene-specific version of SOM was used (see Supplement for details). IVOC yields are derived from the explicit model GECKO-A simulations performed for n-alkanes mixtures at low (0.1 ppb) and high $(10 \mathrm{ppb}) \mathrm{NO}_{x}$ levels. For SOM and GECKO-A fits, yields were derived assuming background OA concentrations of $10 \mu \mathrm{g} \mathrm{m}^{-3}$.

\begin{tabular}{rrrrrrrr}
\hline Precursor & IVOC & TERP & ISOP & BENZ & TOL & XYL & SESQ \\
\hline$M_{\mathrm{W}}\left(\mathrm{g} \mathrm{mol}^{-1}\right)$ & 189 & 136 & 68 & 78 & 92 & 106 & 204 \\
\hline$k_{\mathrm{OH} @ 298 \mathrm{~K}\left(\mathrm{~s}^{-1}\right)} 1.34 \times 10^{-11}$ & $5.3 \times 10^{-11}$ & $10^{-10}$ & $1.22 \times 10^{-12}$ & $5.63 \times 10^{-12}$ & $2.31 \times 10^{-11}$ & $5.3 \times 10^{-11}$ \\
\hline $\log \left[C^{*}\right]$ & & & & Mass yields at low NO & & \\
\hline$<-2$ & 0.315 & 0.093 & 0.012 & 0.007 & 0.371 & 0.395 & 0.270 \\
-1 & 0.173 & 0.211 & 0.013 & 0.003 & 0.028 & 0.041 & 0.253 \\
0 & 0.046 & 0.064 & 0.001 & 0.270 & 0.207 & 0.203 & 0.080 \\
1 & 0.010 & 0.102 & 0.100 & 0.142 & 0.586 & 0.121 & 0.157 \\
2 & 0.007 & 0.110 & 0.078 & 0.400 & 0.063 & 0.232 & 0.068 \\
3 & 0.008 & 0.125 & 0.097 & 0.120 & 0.138 & 0.145 & 0.072 \\
\hline-2 & & & & Mass yields at high $\mathrm{NO}_{x}$ & & & \\
\hline 1 & 0.140 & 0.045 & 0.001 & 0.031 & 0.042 & 0.015 & 0.157 \\
0 & 0.136 & 0.015 & 0.001 & 0.011 & 0.123 & 0.056 & 0.220 \\
1 & 0.069 & 0.142 & 0.027 & 0.507 & 0.263 & 0.006 & 0.083 \\
2 & 0.019 & 0.061 & 0.021 & 0.019 & 0.020 & 0.026 & 0.097 \\
3 & 0.010 & 0.074 & 0.044 & 0.030 & 0.319 & 0.087 & 0.054 \\
& 0.012 & 0.165 & 0.185 & 0142 & 0.329 & 0.193 & 0.100 \\
\hline
\end{tabular}

and $\Delta[\mathrm{HC}]$ is the reacted amount of a given parent hydrocarbon. All species with $\log C_{\mathrm{SOM}, i}^{*}<-2.5$ were added to the $\log C_{\mathrm{VBS}}^{*}=-2 \mathrm{bin}$. This produces a VBS for each compound for use in the global simulations that effectively accounts for the influence of vapor wall losses and, to first order the long-time influence of multi-generational chemistry. This new set of parameters used in the VBS_NEW model is summarized in Table 1 for low- and high- $\mathrm{NO}_{x}$ SOA production from monoterpenes, isoprene, sesquiterpenes, benzene, toluene and xylene. Similar to Jo et al. (2013), we use the low- $\mathrm{NO}_{x}$ yield values for biogenic species since most of the biogenic emissions occur over low- $\mathrm{NO}_{x}$ forested regions and since the coarse model resolution cannot resolve high- $\mathrm{NO}_{x}$ conditions. This is also consistent with the previous global model study by Pye and Seinfeld (2010), which reported that more than $90 \%$ of biogenic hydrocarbon reactions proceed through the low-NO $x$ pathway. For anthropogenic species, we perform a linear interpolation between low- and high$\mathrm{NO}_{x}$ values for anthropogenic species based on the relative ratio of $\mathrm{HO}_{2}$ and $\mathrm{NO}$ at the location and time of VOC oxidation (Lane et al., 2008). The range of volatilities was extended to six bins, from 0.01 to $1000 \mu \mathrm{g} \mathrm{m}^{-3}$ at $300 \mathrm{~K}$ for all species. The enthalpy of vaporization was updated to the experimentally derived values starting at $151 \mathrm{~kJ} \mathrm{~mol}^{-1}$ at $C^{*}=0.01 \mu \mathrm{g} \mathrm{m}^{-3}$ and decreasing by $11 \mathrm{~kJ} \mathrm{~mol}^{-1}$ for each increase in order of magnitude of $C^{*}$ (Epstein et al., 2010).

The artificial aging of anthropogenic oxidation products is no longer considered in this updated model. However, it is important to note that the SOM accounts for multi- generational oxidation implicitly, including both functionalization and fragmentation reaction pathways, while the VBS type models do not. Therefore, when VBS_NEW yield distributions are determined from the corrected yield curves (or even when determined from the uncorrected yield curves) the influence of multi-generational oxidation (aging) on the observed SOA formation is, to some extent, captured in the derived VBS yield parameters even though the VBS fits assume the OVOC product species are unreactive. In contrast, the aging reactions included in the base-case VBS_REF model above (Sect. 2.1., REF run) are added ad hoc on top of the original parameterization, which can lead to substantial overestimates of the SOA formation (Jathar et al., 2016; Dzepina et al., 2011; Lane et al., 2008). The addition of this ad hoc aging results in higher yields and the formation of less volatile organic species from anthropogenic precursors in the default VBS_REF model (Jo et al., 2013) compared to the updated VBS_NEW as demonstrated for Toluene in Fig. S2.

It is worth noting that the chamber data set used here to determine the modified VBS_NEW parameters is not identical to that used to determine the base-case VBS_REF parameters. However, Jathar et al. (2016) have demonstrated that there are relatively small differences between the amounts of SOA simulated using the new data set vs. using a traditional set of parameters when a two-product approach is used, which suggests that this data set difference should have minimal influence on the VBS_NEW simulations here. The method used here to determine the modified VBS_NEW parameters (fitting of a vapor wall-loss adjusted synthetic data 
set) is an extension of the approach of Cappa et al. (2016), where they fitted a set of two-product yields (Odum et al., 1996) to the synthetic (wall-loss-corrected) model runs, and where they found that the two-product model fits were not sufficiently robust due to the limited number of fit parameters. The use of a six-product parameterization here was found to allow for reasonable fits to the synthetic yield curves. The difference between uncorrected yields and wallcorrected yields (1.1 to 4.1 times) is shown in the Supplement (Fig. S3).

In this study, we also include SOA formation from the oxidation of long-chain n-alkanes $(C>12)$ emitted from fossilfuel, biofuel and biomass burning sources (e.g., Robinson et al., 2007; Gentner et al., 2012). These SVOC and IVOC are typically not included in traditional emission inventories. This gap arises from the fact that SVOCs are lost rapidly by evaporation upon dilution are thus not accounted for as primary emissions, and as well as a typical lack of characterization and quantification IVOC compounds in emission studies. Based on the analysis by Jathar et al. (2014, their Table 1), we set SVOC mass emissions as $60 \%$ of POA emissions and IVOC emissions as $20 \%$ of NMVOC (nonmethane volatile organic compounds) emissions (not including SVOC emissions) in each grid cell. We consider both anthropogenic and biomass burning emissions of S/IVOC. The emitted S/IVOCs can undergo oxidation with $\mathrm{OH}$ in the model and produce OVOCs that can partition to form SOA. Table 1 shows the volatility distribution of produced OVOCs (and thus the corresponding SOA yields) that were derived from the GECKO-A model (Generator of Explicit Chemistry and Kinetics of Organics in the Atmosphere; Aumont et al., 2005) for low- and high- $\mathrm{NO}_{x}$ conditions, considering a mixture of n-alkane species shown in Table 3 (Lee-Taylor et al., 2011). GECKO-A explicitly accounts for the multigenerational oxidation of OVOCs, including both functionalization and fragmentation reaction pathways, and thus the multi-generational aging of OVOCs from S/IVOCs is implicitly built into the VBS_NEW parameterization provided in Table 1. For GECKO-A, VBS yield distributions were derived in a similar manner as was done for determining distributions from SOM for the other SOA precursors (discussed above), assuming background OA concentrations of $10 \mu \mathrm{g} \mathrm{m}^{-3}$ and simulation conditions similar to Hodzic et al. (2014). For computational efficiency, OVOC formation from SVOC was mapped to that of IVOCs by increasing the yields by $20 \%$, which corresponds to the ratio in mass yields between SVOC and IVOCs as calculated from GECKO-A.

Global annual mean (2005-2008) emissions of S/IVOC were estimated to be about $54 \mathrm{Tg} \mathrm{yr}^{-1}$ (split evenly between biomass burning and fossil/biofuels source categories) based on the corresponding emissions of POA (36.8 $\mathrm{Tg} \mathrm{yr}^{-1}$ biomass burning; $19.7 \mathrm{Tg} \mathrm{yr}^{-1}$ fossil- and biofuels) and of NMVOC (23.7 $\mathrm{Tg} \mathrm{yr}^{-1}$ biomass burning; $74.9 \mathrm{Tg} \mathrm{yr}^{-1}$ fossil- and biofuels). The resulting production of secondary organic gases with the updated VBS_NEW parameteriza- tion is $\sim 14 \mathrm{Tg} \mathrm{yr}^{-1}$ for biomass burning sources and an additional $\sim 14 \mathrm{Tg} \mathrm{yr}^{-1}$ for fossil- and biofuel sources. Our S/IVOC emission estimates are on the low side of the values used in previous studies. For example, Shrivastava et al. (2015) assumed that S/IVOC emissions were 6.5 times those of POA from biomass burning and fossil fuels (i.e. $\sim 450 \mathrm{Tg} \mathrm{yr}^{-1}$ of $\mathrm{S} / \mathrm{IVOC}$ gases from emissions including the addition of oxygen during functionalization). However, by including fragmentation of oxidized organic gases in the best-estimate run the effective S/IVOC source is reduced to 1.5-3 times POA emissions. Jathar et al. (2011) assumed that IVOC emissions $\left(84.6 \mathrm{Tg} \mathrm{yr}^{-1}\right.$ ) were 1.5 times those of POA, which led to the formation of $27.3 \mathrm{Tg} \mathrm{yr}^{-1}$ of SOA (close to our estimates of total SOA from S/IVOC). They also modeled POA emissions (56.4 $\mathrm{Tg} \mathrm{yr}^{-1}$ ) as SVOC gases, assuming that POA was semi-volatile following the volatility distribution of Robinson et al. (2007), that SVOC oxidation formed $22.5 \mathrm{Tg} \mathrm{yr}^{-1}$ of SOA and that the rest equilibrated to form POA.

\subsection{Updated parameterization of SOA removal}

\subsubsection{Dry and wet deposition}

In GEOS-Chem, soluble gases and aerosols are removed by both convective and grid-scale precipitation as described by Liu et al. (2001). Similar to other global model studies, a fixed value of the effective Henry's law solubility coefficient $\left(H^{\text {eff }}\right)$ of $10^{5} \mathrm{M} \mathrm{atm}^{-1}$ was used in the base model configuration for all intermediate OVOC gas-phase species that can partition to form SOA (Jo et al., 2013). Aerosol wet scavenging efficiency is set to $80 \%$ as in the standard GEOS-Chem model (Chung and Seinfeld, 2002). We modified the model to account for the volatility dependence of the Henry's law water solubility coefficients for these species based on Hodzic et al. (2014). $H^{\text {eff }}$ values used are summarized in Table 2. For traditional anthropogenic precursors, we use $H^{\text {eff }}$ typical of oxidation products of n-alkanes while for biogenic precursors we use $H^{\text {eff }}$ values typical of oxidation products of monoterpenes. For oxidation products of IVOCs, we use $H^{\text {eff }}$ of $10^{3} \mathrm{Matm}^{-1}$.

Dry deposition of organic gases and particles is represented by the standard resistance approach (Wesely, 1989; Seinfeld and Pandis, 2006), which depends on meteorological conditions through atmospheric and laminar resistances, surface type through the surface resistance and gravitational settling velocity for particles. The surface resistance describes partitioning of gases into plants and wet surfaces. For particles the surface resistance is set to zero as particles are assumed to stick to the surface. We note, however, that the GEOS-Chem configuration used by Jo et al. (2013) did not include dry deposition of organic vapors. In this study, we include dry deposition of organic vapors using the same volatility-dependent Henry's law coefficients as in the wet deposition parameterization (Table 2). 
Table 2. Henry's law constants used in this study based on values reported in Hodzic et al. (2014). $H^{\text {eff }}$ of the oxidation products of n-alkanes is used for oxidation products of all anthropogenic precursors, whereas $H^{\text {eff }}$ of the oxidation products of monoterpenes is used for those of biogenics. For products of IVOCs used in Table 1, we use $H^{\text {eff }}=10^{3} \mathrm{M} \mathrm{atm}^{-1}$.

\begin{tabular}{lrrrrrr}
\hline Saturation concentrations $\left(\mu \mathrm{g} \mathrm{m}^{-3}\right)$ & 0.01 & 0.1 & 1 & 10 & 100 & 1000 \\
\hline Anthropogenic: $H^{\text {eff }}$ n-alkanes $\left(\mathrm{M} \mathrm{atm}^{-1}\right)$ & $1.3 \times 10^{7}$ & $3.2 \times 10^{5}$ & $4.0 \times 10^{5}$ & $1.3 \times 10^{5}$ & $1.6 \times 10^{5}$ & $10^{5}$ \\
Biogenic: $H^{\text {eff }}$ monoterpenes $\left(\mathrm{M} \mathrm{atm}^{-1}\right)$ & $7.9 \times 10^{11}$ & $6.3 \times 10^{10}$ & $3.2 \times 10^{9}$ & $6.3 \times 10^{8}$ & $3.2 \times 10^{7}$ & $1.3 \times 10^{7}$ \\
\hline
\end{tabular}

\subsubsection{Photolytic removal of particle-phase organics}

We also include the SOA loss by photolysis as a first-order reaction following the parameterization proposed by Hodzic et al. (2015). We assume that absorption of each photon by an SOA molecule leads to the irreversible loss of one carbon atom (as the lowest possible limit) from the molecule with a quantum yield of QY. With this assumption, the loss rate of SOA can be written as

$\mathrm{d}[\mathrm{SOA}] / \mathrm{d} t=-J_{\mathrm{SOA}} \times[\mathrm{SOA}]$, where

$J_{\mathrm{SOA}}=\mathrm{AF} \times \mathrm{MAC} \times \mathrm{QY} \times m_{\mathrm{c}}$.

In these equations, $J_{\mathrm{SOA}}$ is the first-order photolysis rate coefficient for SOA integrated over the $280-400 \mathrm{~nm}$ wavelength range, $[\mathrm{SOA}]$ is the SOA mass concentration $\left(\mathrm{g} \mathrm{m}^{-3}\right), \mathrm{AF}$ is the total actinic flux over $280-400 \mathrm{~nm}$ (photons $\mathrm{m}^{-2} \mathrm{~s}^{-1}$ ), MAC is the SOA mass absorption coefficient $\left(\mathrm{m}^{2} \mathrm{~g}^{-1}\right), \mathrm{QY}$ is the quantum yield (atoms of $\mathrm{C}_{\text {photon }}{ }^{-1}$ ) and $m_{\mathrm{c}}$ is mass of a $\mathrm{C}$ atom $(\mathrm{g}) . J_{\mathrm{SOA}}$ can be rewritten in terms of the $\mathrm{NO}_{2}$ photolysis rate coefficient $\left(J_{\mathrm{NO}_{2}}\right)$ as

$J_{\mathrm{SOA}}=2 \times 10^{22} \times J_{\mathrm{NO}_{2}} \times \mathrm{MAC} \times \mathrm{QY} \times m_{\mathrm{c}}$

where $2 \times 10^{22}$ (in units of photons $\mathrm{m}^{-2}$ ) is the value of $\left[\mathrm{AF} / \mathrm{NO}_{2}\right]$ estimated by the photolysis model TUV (http://cprm.acom.ucar.edu/Models/TUV/Interactive_TUV/) (Madronich, 1993) for overhead sun conditions at $1 \mathrm{~km}$ altitude over $280-400 \mathrm{~nm}$. This value varies by only $\pm 5 \%$ over a range of solar zenith angles $\left(0\right.$ to $\left.90^{\circ}\right)$, altitudes ( 1 to $10 \mathrm{~km}$ ), overhead ozone column (250 to 400 Dobson units), and summer and winter conditions.

Similar to Hodzic et al. (2015), here we use $\mathrm{MAC}=0.1 \mathrm{~m}^{2} \mathrm{~g}^{-1}$ and $\mathrm{QY}=0.01$ (or $1 \%$ ) as a representative value for ambient SOA aerosols. The resulting value for $J_{\mathrm{SOA}}$ is $0.04 \%$ of $J_{\mathrm{NO}_{2}}\left(J_{\mathrm{SOA}}=4 \times 10^{-4} \times J_{\mathrm{NO}_{2}}\right)$, which is more than an order of magnitude lower than the photolysis loss coefficients reported by Henry and Donahue (2012), who estimated the photolytic loss of SOA as $2 \%$ of $J_{\mathrm{NO}_{2}}$ (average value of the net effect of both particle and gas-phase photolysis). It should be noted that the implicit assumption in this formulation is that only one carbon atom is lost upon SOA photolysis reaction and not the entire SOA molecule. For more details on the parameterization we refer readers to a previous study by Hodzic et al. (2015) that presents a detailed discussion of
Table 3. Chemical speciation of the considered SVOC and IVOC mixtures in GECKO-A (Lee-Taylor et al., 2011).

\begin{tabular}{llrr}
\hline \multirow{2}{*}{ Surrogate } & Species & No. C & $\begin{array}{r}\text { Mass contribution } \\
\text { to surrogate }\end{array}$ \\
\hline IVOC & n-dodecane & 12 & $22.50 \%$ \\
& n-tridecane & 13 & $20.80 \%$ \\
& n-tetradecane & 14 & $15.70 \%$ \\
& n-pentadecane & 15 & $11.30 \%$ \\
& n-hexadecane & 16 & $10.60 \%$ \\
& n-heptadecane & 17 & $8.00 \%$ \\
& n-octadecane & 18 & $7.50 \%$ \\
& n-nonadecane & 19 & $3.60 \%$ \\
\hline SVOC & n-nonadecane & 19 & $9.10 \%$ \\
& n-eicosane & 20 & $17.40 \%$ \\
& n-heneicosane & 21 & $16.60 \%$ \\
& n-docosane & 22 & $9.50 \%$ \\
& n-tricosane & 23 & $9.10 \%$ \\
& n-tetracosane & 24 & $7.70 \%$ \\
& n-pentacosane & 25 & $6.50 \%$ \\
& n-hexacosane & 26 & $6.20 \%$ \\
n-heptacosane & 27 & $3.90 \%$ \\
& n-octacosane & 28 & $3.70 \%$ \\
n-nonacosane & 29 & $3.00 \%$ \\
n-triacontane & 30 & $7.30 \%$ \\
\hline
\end{tabular}

the comparability of the photolysis rate estimates used in his study with the laboratory-derived estimates of Henry and Donahue (2012) and also discusses the impact of faster photolysis rates on modeled SOA distributions.

\subsubsection{Heterogeneous reaction with ozone}

The removal of organic molecules by heterogeneous reactions at the surface of particles was also implemented into the updated GEOS-Chem model. Reported values of the reactive uptake coefficient $(\gamma)$, which represents the probability that a reaction occurs upon gas-surface collision, span several orders of magnitude. Values of $\gamma$ for the uptake of $\mathrm{OH}$ radicals range from 0.1 to 1.0 (George and Abbatt, 2010), whereas for $\mathrm{NO}_{3}$ and $\mathrm{O}_{3}$ the uptake kinetics vary considerably depending on the phase and chemical composition of the organic surface. Values of $\gamma$ for heterogeneous reactions of $\mathrm{O}_{3}$ with unsaturated organics are typically $\sim 10^{-3}$ for liquidphase organics and an order of magnitude smaller, $5 \times 10^{-5}$ 
to $10^{-4}$, for solid organics as the reactants are confined to the surface due to decreased diffusion coefficients into the bulk of the particle (Moise and Rudich, 2002; Hearn and Smith, 2004). The $\mathrm{O}_{3}$ reaction is less efficient with liquid aldehydes and ketones $\left(\gamma=10^{-4}\right.$; de Gouw and Lovejoy, 1998), alkanes $\left(\gamma=2 \times 10^{-5}\right.$ for hexadecane; Moise and Rudich, 2000) or alcohols ( $\gamma \leq 10^{-5}$; De Gouw and Lovejoy, 1998). For $\mathrm{NO}_{3}$, Moise et al. (2002) reported $\gamma$ values ranging from $1.5 \times 10^{-2}$ to $3.8 \times 10^{-4}$ for a variety of organics including alkanes, alkenes, alcohols and carboxylic acids with saturated and unsaturated bonds.

Given the range of uncertainties, here we estimate the potential effect on SOA removal by $\mathrm{OH}, \mathrm{NO}_{3}$ and $\mathrm{O}_{3}$ heterogeneous oxidation for typical conditions. Aerosol particles consist of molecules that are reactive with these oxidants. The rate of loss of the gas-phase oxidants is equal to

$$
\left.\left[\frac{\mathrm{d} \text { [oxidant }]}{\mathrm{d} t}\right]_{\mathrm{het}}=1 / 4 \times \gamma \times[\text { oxidant }] \times<c\right\rangle \times A,
$$

where [oxidant] is the oxidant concentration, $\langle c\rangle$ is the mean gas-phase speed of the oxidant and $A$ is the specific surface area of organic aerosols (per unit volume of air). This formulation does not account for diffusion limitations. We assume that each oxidant lost from the gas-phase reacts with one molecule of $\mathrm{OA}$ and that $10 \%$ of the OA mass is lost as a result. For $\mathrm{O}_{3}=10^{12}$ molecules $\mathrm{cm}^{-3}, A=10^{-5} \mathrm{~m}^{2} \mathrm{~m}^{-3}$ and $\gamma=10^{-5}$, the bulk SOA mass loss rate is about $4 \%$ per day. For $\mathrm{OH}$, assuming $\gamma$ values of $0.1-1$ and a concentration of $10^{6}$ molecules $\mathrm{cm}^{-3}$, the corresponding SOA loss rate is about 6-60 times slower. For $\mathrm{NO}_{3}$, assuming $\gamma=0.01$ and a concentration of $10^{7}$ molecules $\mathrm{cm}^{-3}$, the corresponding SOA loss rate is about 100 times lower than the loss rate due to reaction with $\mathrm{O}_{3}$.

Given these estimates, we only consider the surface oxidation loss by $\mathrm{O}_{3}$ with $\gamma=10^{-5}$ in the GEOS-Chem sensitivity simulations presented in this study. The chosen uptake coefficient is 1-2 orders of magnitude lower than the reported values for unsaturated organics, which accounts for the fact that unsaturated organic compounds are only a minor fraction of the total organic aerosol and the fact that values for other compounds are $\gamma \leq 2 \times 10^{-5}$. In each grid cell and at each chemical time step, the loss rate of SOA due to heterogeneous oxidation by $\mathrm{O}_{3}$ is calculated on the basis of the local organic aerosol surface area and $\mathrm{O}_{3}$ concentration.

\subsection{Model simulations}

Five model simulations were performed for the 2005-2008 period. Their characteristics are listed in Table 4. The basecase simulation (REF) corresponds to the model setup as used in the previous simulations by Jo et al. (2013) and is typical of other global model studies in which the VBS framework is used. The sensitivity simulations are designed to study the effect of new wall-corrected chamber yields and SOA production from S/IVOCs (NY), updated dry and wet deposition of organic vapors (NY_D), and photolytic (NY_DP) and heterogeneous (NY_DPH) loss of SOA. Each of the sensitivity simulations builds successively on the NY simulation. For example, the NY_DP simulation adds updated Henry's law coefficients and photolytic SOA loss to the new yields simulation, and the NY_ DPH adds heterogeneous chemistry SOA loss to the NY_DP simulation (Table 4). The overall effect of new removal pathways on SOA global budgets was estimated by comparing the NY and NY_DPH runs.

\subsection{Data used for model evaluation}

\subsubsection{Ground measurements}

Over the continental USA, model results are evaluated using surface organic carbon (OC) measurements (in $\mathrm{PM}_{2.5}$ filter samples collected every 3 days) from the IMPROVE network (Interagency Monitoring of Protected Visual Environments, http://aqsdr1.epa.gov/aqsweb/aqstmp/ airdata/download_files.html). For the comparison, measurements taken from 2005 to 2008 are used (more than 76000 data points), and data were averaged over the entire period for each month. Measurements are mostly representative of rural background OC concentrations since the IMPROVE sites are, for the most part, located in US national parks. Over Europe, the monthly mean observations of OC (in $\mathrm{PM}_{10}$ samples) collected at the EMEP (European Monitoring and Evaluation Programme, http://ebas.nilu.no; Yttri et al., 2007) sites from 2002 to 2003 are used to evaluate GEOS-Chem monthly mean results. We only use data from the rural background sites (see Table S4). Both the IMPROVE and EMEP site measurements determined OC concentrations using thermo-optical methods. During the considered period, the mean OC concentration are 2.5 times larger at the EMEP sites $\left(3.46 \mu \mathrm{g} \mathrm{m}^{-3}\right)$ than at the IMPROVE sites $\left(1.27 \mu \mathrm{g} \mathrm{m}^{-3}\right)$, which could be due to a greater proximity of urban and industrial centers. Evaporation of OC from IMPROVE summer samples, which are kept in the field for several days and shipped without cooling, could also play a role (Kim et al., 2015).

Surface measurements from the aerosol mass spectrometer (AMS) global network for years 2000-2008 (Zhang et al., 2007; https://sites.google.com/site/amsglobaldatabase/) are used to evaluate modeled SOA. The bulk OA observations have been further analyzed through positive matrix factorization to assess contributions from different OA types, or factors, and are divided into two key OA types, i.e., oxygenated OA (OOA) and hydrocarbon-like OA (HOA). We assume that the observed OOA can be directly compared with model predicted SOA. Multi-year (2005-2008) monthly means from the model are compared with the corresponding observations reported at 20 locations, including 16 rural and 4 background locations (urban site were not considered). 
Table 4. Description of the GEOS-Chem simulations performed for years 2004-2008.

\begin{tabular}{lllll}
\hline Simulation & Production & $H_{\text {eff }}\left(\mathrm{M} \mathrm{atm}^{-1}\right)$ for dry and wet deposition & SOA photolysis & SOA $+\mathrm{O}_{3}$ \\
\hline REF & VBS_REF (Jo et al., 2013) & $10^{5}$ & NO & NO \\
NY & VBS_NEW (Table 1) & $10^{5}$ & NO & NO \\
NY_D & VBS_NEW (Table 1) & Volatility-dependent $H^{\text {eff }}$ & NO & NO \\
NY_DP & VBS_NEW (Table 1) & Volatility-dependent $H^{\text {eff }^{\mathrm{a}}}$ & $4 \times 10^{-4} \times J_{\mathrm{NO}_{2}}{ }^{\mathrm{b}}$ & NO \\
NY_DPH & VBS_NEW (Table 1) & Volatility-dependent $H^{\text {eff }}$ & $4 \times 10^{-4} \times J_{\mathrm{NO}_{2}}{ }^{\mathrm{a}}$ & YES \\
\hline
\end{tabular}

a Based on the $H^{\text {eff }}$ parameterization by Hodzic et al. (2014); ${ }^{\mathrm{b}}$ from Hodzic et al. (2015).

\subsubsection{Aircraft measurements}

We use OA measurements from recent aircraft field campaigns (https://sites.google.com/site/amsglobaldatabase/ aircraft, Heald et al., 2011; SEAC4RS data can be found at http://www-air.larc.nasa.gov) that took place between 2005 and 2013 to evaluate the vertical distribution of organic aerosols (see Table S5). The comparison is performed for conditions representative of remote (ITOP IMPEX, VOCALS-UK), moderately polluted (SEAC4RS, ADRIEX, TexAQ, EUCAARI) and biomass burning influenced (ARCTAS) regions. Given the coarse model resolution, data from heavily polluted regions (e.g., Mexico City MILAGRO, Asia ACE-Asia, Borneo OP3) were not considered. In these campaigns, total OA concentrations were measured using the AMS instrument (Canagaratna et al., 2007). Observations were averaged over each aircraft campaign according to their vertical location and compared to the simulated monthly mean OA vertical profiles in the corresponding month and location in the model. For ARCTAS, the observed OA concentrations above the 99th percentile, i.e., larger than $16 \mu \mathrm{g} \mathrm{m}^{-3}$ (STP) (where "STP" stands for standard conditions of $273.15 \mathrm{~K}$ and $1013.25 \mathrm{hPa}$ ), were filtered out to limit the influence of biomass burning plumes that the GEOSChem model cannot resolve at the considered horizontal resolution. For SEAC4RS, the 80th percentile value of acetonitrile $(\sim 140 \mathrm{ppt})$ was used as a cut-off to exclude OA measurements heavily influenced by fire plumes. For three campaigns (ITOP, ADRIEX and SEAC4RS) that occurred outside of the modeled period, we used averaged model values between 2005 and 2008 for the month corresponding to the field project.

\section{Results and discussion}

\subsection{SOA spatial distribution}

The spatial distribution of annual mean (2005-2008) concentrations of SOA from various sources (total, biogenic VOC, anthropogenic and biomass burning VOC, and anthropogenic and biomass burning S/IVOC) in the lower troposphere (ground to $5 \mathrm{~km}$ a.g.l.) as predicted by the GEOS-
Chem NY run are shown in Fig. 1. The simulated continental background SOA levels in the lower troposphere are typically between 0.2 and $0.5 \mu \mathrm{g} \mathrm{m}^{-3}$, and the highest concentrations $\left(>2 \mu \mathrm{g} \mathrm{m}^{-3}\right)$ are predicted over tropical forest regions of Africa and South America. Industrialized and urban areas in China, Europe and the USA feature SOA concentrations significantly larger $\left(1-2 \mu \mathrm{g} \mathrm{m}^{-3}\right)$ than the background. The biggest contribution to SOA worldwide is from biogenic sources. The predicted spatial distribution and amounts of biogenic SOA, with high values over tropical forest regions, are consistent with previous modeling studies (e.g., Farina et al., 2010; Shrivastava et al., 2015) and somewhat larger than concentrations estimated by Spracklen et al. (2011). Anthropogenic emissions of traditional hydrocarbons (aromatics and short n-alkanes) contribute up to $0.5 \mu \mathrm{g} \mathrm{m}^{-3}$ over industrialized and urban regions and about $0.1 \mu \mathrm{g} \mathrm{m}^{-3}$ elsewhere. The contribution of intermediate and semi-volatile anthropogenic compounds, which are not treated in traditional emission inventories, is significant, ranging from $0.1 \mu \mathrm{g} \mathrm{m}{ }^{-3}$ background levels to $0.5 \mu \mathrm{g} \mathrm{m}^{-3}$ over continental Europe and North America and 1-2 $\mu \mathrm{g} \mathrm{m}^{-3}$ over polluted regions of China and India, as well as over tropical biomass burning regions in Africa and South America. Spatial patterns and concentrations of SOA predicted from S/IVOCs are within similar to those reported by Jathar et al. (2011, Fig. 4).

\subsubsection{Effect of wall-corrected chamber yields}

Figure 1 also shows the difference between the NY simulation, using the vapor wall-loss-corrected yields for SOA formation from traditional anthropogenic and biogenic precursors, and the REF simulation using the typical non-corrected yields with artificial aging of intermediate organic vapors produced from anthropogenic precursors as in previous studies (Farina et al., 2010; Jo et al., 2013). In terms of annual averages, the difference between the two simulations shows an increase in biogenic SOA of $\sim 1 \mu \mathrm{g} \mathrm{m}^{-3}$ over eastern USA, Australia and southeast Asia and up to $4-8 \mu \mathrm{g} \mathrm{m}^{-3}$ over SOA hotspots of tropical Africa and South America. This change can be attributed to effectively higher SOA yields and the formation of less volatile SOA as shown in Fig. S2. SOA formation from the traditional anthropogenic VOC precursors is decreased in the NY simulation by 0.1 to $0.3 \mu \mathrm{g} \mathrm{m}^{-3}$. 


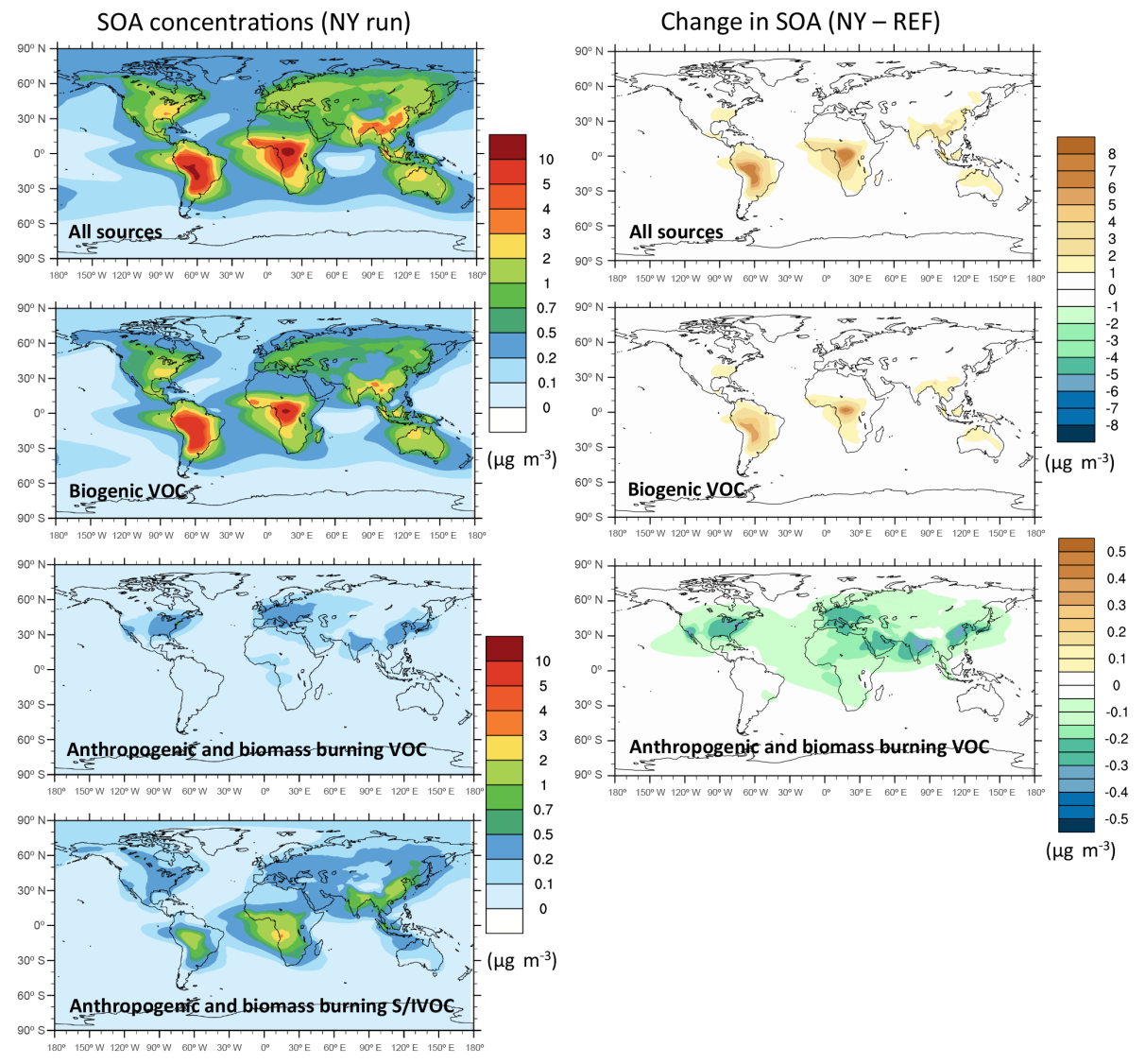

Figure 1. Average concentrations for SOA and its constituents during 2005-2008 as predicted by the GEOS-Chem NY run in the lower troposphere (surface to $5 \mathrm{~km}$; left column). Total SOA is separated into SOA from biogenic VOCs, anthropogenic and biomass burning traditional VOCs, and anthropogenic and biomass burning S/IVOC. The NY run is also compared with REF (right column).

The wall-corrected yields for aromatics are lower than the traditional yields combined with the aging parameter, which were used in the default version of the model (see Fig. S2). This difference is primarily due to the addition of aging reactions in the REF model, which leads to substantial and likely excessive production of SOA as discussed in Dzepina et al. (2011) and Jathar et al. (2016). However, the total anthropogenic fraction is increased in the NY simulation by $\sim 0.5 \mu \mathrm{g} \mathrm{m}^{-3}$ over southeast Asia, and up to $\sim 2 \mu \mathrm{g} \mathrm{m}^{-3}$ over south America and Africa due to the contribution of intermediate and semi-volatile compounds that were only accounted for in the NY simulation. Vertical profiles of SOA concentrations averaged over the entire globe or the continental USA (Fig. 2) show that SOA production using the vapor wallloss-corrected yields has led to a larger fractional increase of the near-surface SOA concentrations (surface to $3 \mathrm{~km}$ a.g.l.), which is the region where the model underprediction is the most severe (Heald et al., 2011).

\subsubsection{Effect of removal processes}

Figure 3 shows the sensitivity of SOA levels in the boundary layer and in the free troposphere to the three types of removal pathways considered here: dry and wet deposition of organic vapors and aerosols, photolysis and heterogeneous removal of SOA. Given the relatively short chemical lifetime of SOA compared to typical tropospheric transport timescales, there is a strong correspondence between regions where the surface concentrations are highest and where the free-tropospheric concentrations are the highest. Dry and wet removal of gases and particles depends on their water solubility, which is given by the effective Henry's law constant $\left(H^{\text {eff }}\right)$. For organic gases, $H^{\text {eff }}$ has been typically fixed to an arbitrary value in the $10^{3}-10^{5} \mathrm{M} \mathrm{atm}^{-1}$ range. The choice of this value can impact SOA predictions (Bessagnet et al., 2010; Pye and Seinfeld, 2010; Ahmadov et al., 2012; Hodzic et al., 2014; Knote et al., 2015). The comparison between the NY simulation, which uses a constant $H^{\text {eff }}$ of $10^{5} \mathrm{M} \mathrm{atm}^{-1}$ (default value in GEOS-Chem), and the sensitivity NY_D simulation, which uses values determined from the explicit chemical modeling (see Table 2), shows a modest decrease of tropospheric SOA, ranging from 5 to $10 \%$ over water surfaces and from 5 to $20 \%$ over continents (Fig. 3c, i). This suggests that the overall $H^{\text {eff }}$ is somewhat higher than the typical values of $10^{5} \mathrm{M} \mathrm{atm}^{-1}$ used in global 

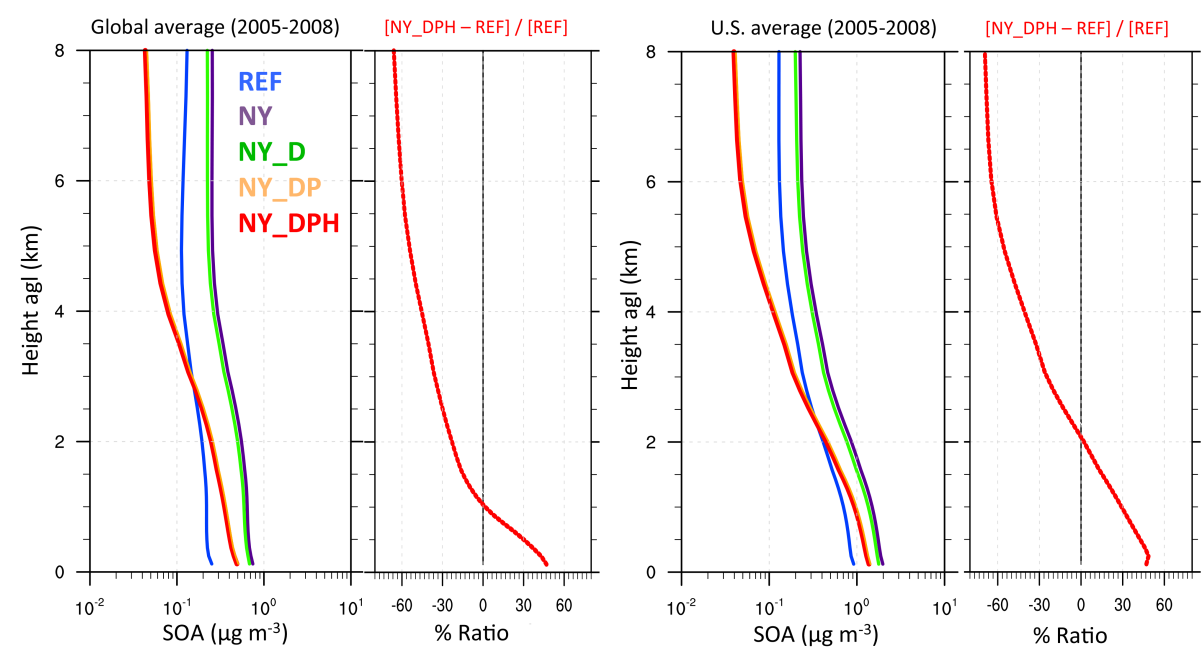

Figure 2. Vertical profiles of average SOA concentrations (at ambient temperature and pressure) integrated globally and regionally over the continental USA between 2005 and 2008. GEOS-Chem predictions from five simulations are shown including REF (blue), NY (purple), NY_D (green), NY_DP (orange) and NY_DPH (red). The ratios between SOA predictions by the NY_DPH and REF runs are also shown for each region.

models. Our results are consistent with Knote et al. (2015, Fig. 9), who showed that over the continental USA SOA levels are decreased by $\sim 20 \%$ when $H^{\text {eff }}$ values based on the explicit chemical modeling were used instead of a constant $H^{\text {eff }}=10^{5} \mathrm{M} \mathrm{atm}^{-1}$. The decrease in SOA results from not only a more limited formation of SOA from oxidized organic vapors because they are removed but also from the evaporation of already formed SOA to satisfy thermodynamic equilibrium. The maximum relative reduction is seen over areas where SOA concentrations are the highest. Figure 2 indicates that there are no significant vertical gradients in SOA reduction (comparing NY_D with NY). The relatively modest impact on SOA concentrations with increased $H^{\text {eff }}$ beyond $10^{5} \mathrm{M} \mathrm{atm}^{-1}$ is expected due to saturation effects as already discussed by Knote et al. (2015), and Hodzic et al. (2014, Fig. S5).

Figure $3 \mathrm{~d}$ and $\mathrm{j}$ show the effect of in-particle photolysis reactions on SOA concentrations using the photolytic loss rate of $0.04 \% J_{\mathrm{NO}_{2}}$ (Hodzic et al., 2015). Annual mean boundary layer SOA concentrations are typically decreased by 10 $30 \%$ over continental regions close to sources and up to $80 \%$ over remote regions. Domain averaged SOA vertical profiles shown in Fig. 2 illustrate more clearly this vertical gradient. The reduction in SOA concentrations ranges from $20 \%$ near surface to $60 \%$ above $4 \mathrm{~km}$ for the NY_DP run compared to the NY_D run. The strong spatial gradient especially between land and water surfaces can be explained by continuous photolytic loss, the effect of which accumulates further away from source regions. Model results show that this loss pathway will play an important role in the regions where wet deposition is not very efficient such as the upper troposphere and lower stratosphere.
Figure $3 \mathrm{e}$ and $\mathrm{k}$ show a $<5 \%$ decrease in SOA boundary layer concentrations over continental areas and a 5-10\% decrease over the outflow regions, when the surface oxidation loss by $\mathrm{O}_{3}$ with $\gamma=10^{-5}$ is considered. Here we did not consider $\mathrm{OH}$ reactions, as our estimates presented in Sect. 2.3.2 suggest that the reaction rate with $\mathrm{OH}$ is 1 to 2 orders of magnitude slower than reaction with $\mathrm{O}_{3}$.

The lifetime of SOA with regard to the combined effect of photolytic loss and heterogeneous reactions with ozone is $\sim 6.2$ days for biogenic SOA, 6.6 days for SOA from aromatic and short-chain VOCs and 6.8 days for SOA from S/IVOCs, which is comparable to the lifetime of SOA against wet removal (3.8-7.4 days). We note that the additional effect of heterogeneous loss of SOA in our simulations is small. Our values are also lower than that reported by Heald et al. (2011) for SOA heterogeneous removal by $\mathrm{OH}$ despite the fact that the inferred global average lifetimes against heterogeneous loss in our simulations (60-70 days) are somewhat lower than the corresponding lifetimes used by (Heald et al., 2011) (80-90 days). This is due to the relatively rapid loss of SOA by photolysis in our simulations. As a consequence, the inclusion of heterogeneous SOA loss in the NY_DPH simulation reduces SOA lifetimes and burdens by only 4-5\% relative the corresponding quantities in the NY_DP simulation.

After studying the effect on SOA concentrations of various loss pathways individually, we assess their combined effect by comparing the NY_DPH vs. NY simulations. The results show a $\sim 30-40 \%$ reduction in annual mean SOA concentrations within the continental boundary layer, and more than $60 \%$ in the outflow remote regions (oceans). A stronger impact on SOA concentrations is found in the free troposphere, with a $40-50 \%$ decrease over continental regions of 

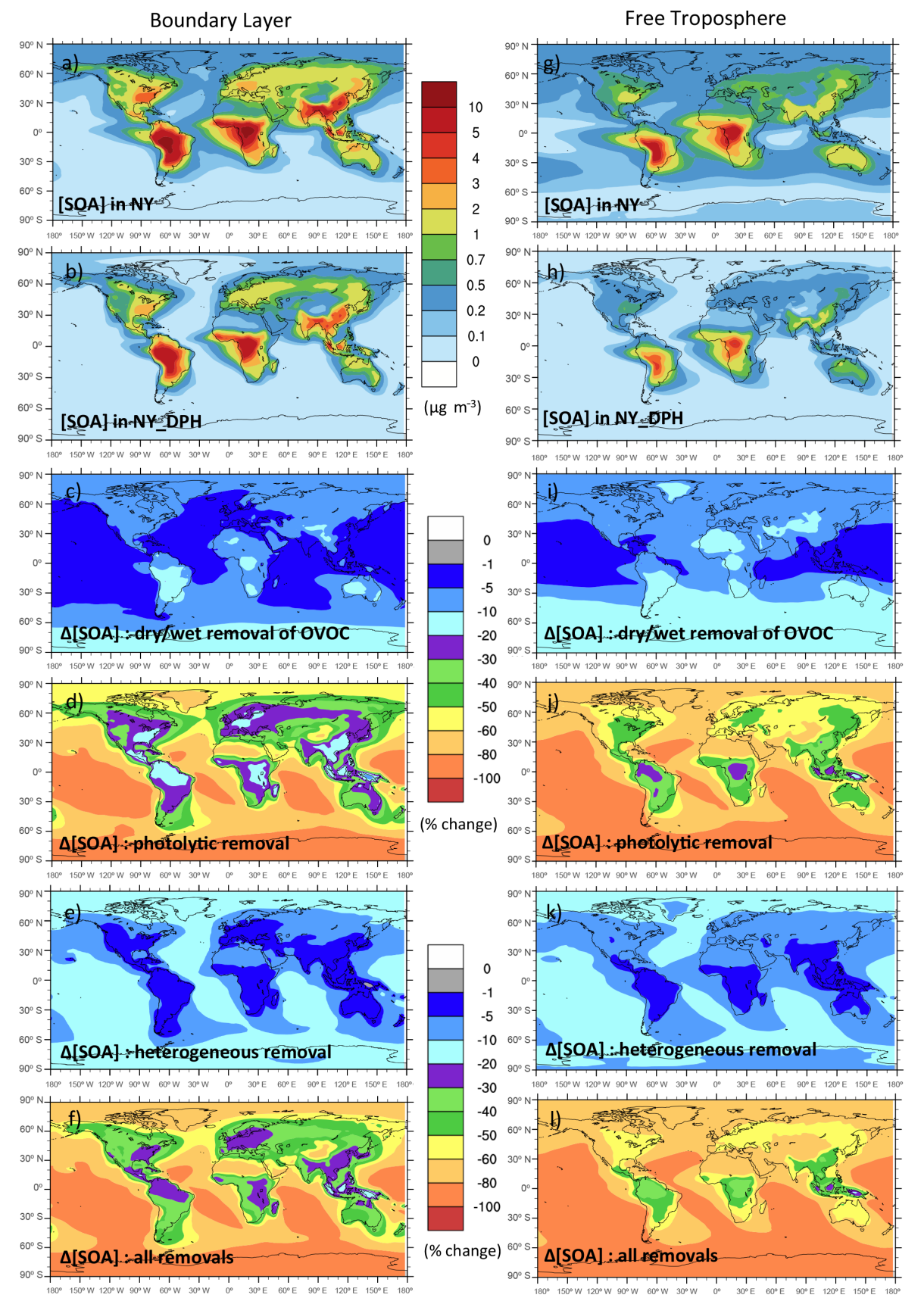

Figure 3. Average SOA concentrations for $2005-2008$ as predicted by NY and NY_DPH runs in the boundary layer (surface to $1.5 \mathrm{~km}$; left column) and in the free troposphere (1.5-5 km; right column). Percent decrease in SOA concentrations resulting from dry/wet removal ([NY_D - NY]/[NY]), photolytic removal ([NY_DP - NY_D]/[NY_D]) and heterogeneous removal ([NY_DPH - NY_DP]/[NY_DP]) of SOA. The combined effect of all considered removal pathways on SOA concentrations is also shown ([NY_DPH - NY]/[NY]).

the Southern Hemisphere and $60 \%$ decrease over continental areas of the Northern Hemisphere. The outflow regions over the Pacific and Atlantic oceans show an $80 \%$ decrease in SOA. SOA concentrations in the NY_DPH simulation (with updated treatment of SOA production and removal) range from background concentrations of $0.1 \mu \mathrm{g} \mathrm{m}^{-3}$ over oceans and $0.5-1 \mu \mathrm{g} \mathrm{m}^{-3}$ over continental areas throughout the lower troposphere to $2-3 \mu \mathrm{g} \mathrm{m}^{-3}$ over urbanized regions of Europe and the USA and $>4 \mu \mathrm{g} \mathrm{m}^{-3}$ over China, India and tropical forest regions of Africa and South America (Fig. 3b). The relative contribution to SOA concentrations of biogenic, anthropogenic and biomass burning VOC and S/IVOC precursors is shown in Fig. S4. We find that biogenic precursors contribute most of the SOA mass in the South- 

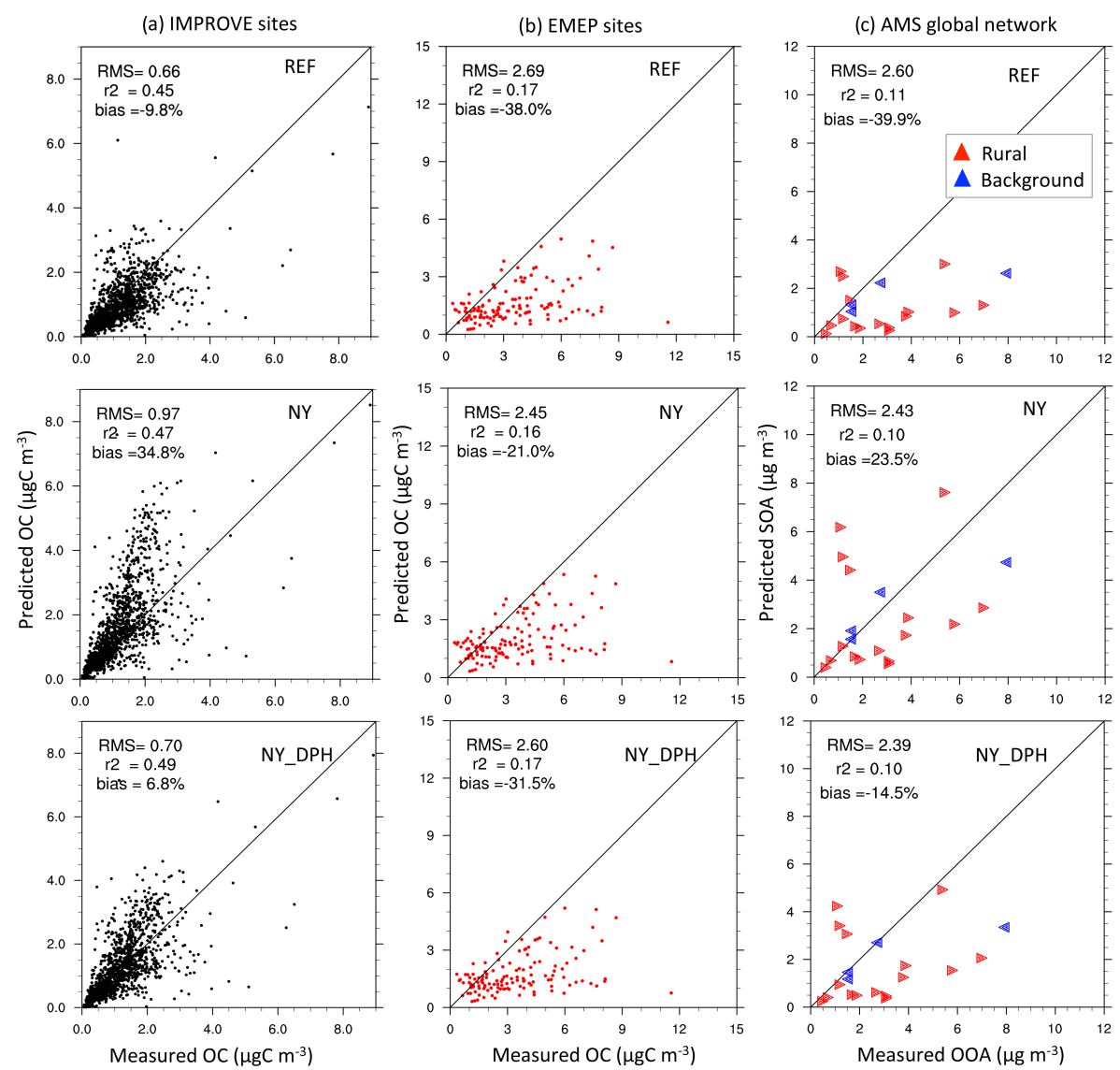

Figure 4. Scatter plots of predicted vs. measured monthly mean OC $\left(\mu \mathrm{gC} \mathrm{m}^{-3}\right)$ and SOA $\left(\mu \mathrm{g} \mathrm{m}^{-3}\right)$ at the surface sites of the US IMPROVE network, the European EMEP network and the global AMS network. AMS data are divided into rural sites (red) and background sites (blue). Given model coarse horizontal resolution, urban sites were not considered.Modeled monthly mean values are representative of years 2005 to 2008 and are compared with monthly mean observations averaged over 2005-2008 for IMPROVE, 2002-2003 for EMEP, and 2000-2008 for AMS sites.

ern Hemisphere and about $\sim 40 \%$ in the Northern Hemisphere, whereas traditional anthropogenic and biomass burning VOC precursors account for $20-30 \%$ over the Northern Hemisphere, and anthropogenic and biomass burning semivolatile and intermediate volatility precursors contribute 30$40 \%$ over China, its outflow region and over tropical regions.

\subsection{Evaluation of the modeled organic aerosol concentration}

The results presented above confirm that the modeled SOA distribution is quite sensitive to the treatment of removal processes. Here, we evaluate the extent to which simulated OA fields using various configurations of the model are consistent with observations. We note that dispersion errors might contribute to discrepancies between observed and modeled OA, but isolating the impact of these errors is difficult (Arellano Jr. et al., 2006). We therefore compare model simulations with a broad suite of OA surface and vertical profile measurements to assess the extent to which they provide sup- port for our alternative hypotheses of SOA sources and sinks. We also note that performance with regards to inorganic aerosol components is documented in Jo et al. (2013), who find that the simulation results are in general agreement with surface observations of sulfate and ammonium but nitrate is overestimated. Model simulations are monthly averaged over the period of 2005-2008 and are compared to the corresponding monthly mean observations taken over multi-year time periods (IMPROVE 2005-2008, EMEP 2002-2003 and AMS 2000-2008). It should be noted that while the IMPROVE and EMEP monitoring networks have generally continuous measurements at fixed sites, the AMS measurements are periodic and thus the average in one specific region is likely representative of the particular year. Similar to previous studies, we ignore year-to-year variability (e.g., Jo et al., 2013). The observed monthly mean concentrations are averaged on the $2 \times 2.5^{\circ}$ model grid. OC concentrations have been estimated from the simulated OA concentrations, which are the sum of anthropogenic and biogenic SOA and POA. POA is tracked in the model as primary organic carbon, and 
(a) IMPROVE data (U.S., 2005-2008)

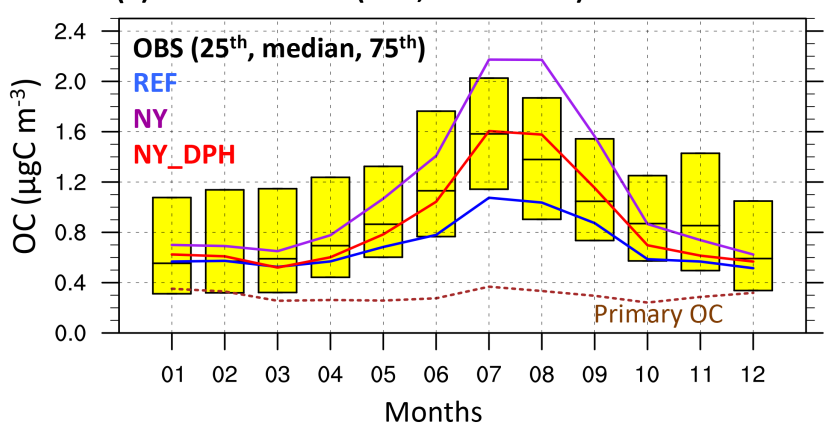

(b) EMEP data (Europe, 2002-2003)

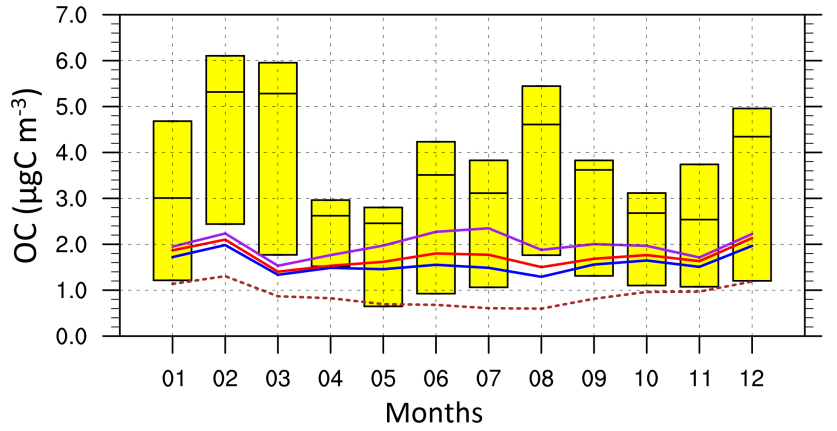

Figure 5. Monthly average OC concentrations as predicted by the GEOS-Chem 2005-2008 simulations and as measured by (a) the IMPROVE network (2005-2008) and (b) the EMEP network (2002-2003). The yellow boxes show the observed medians, 25th and 75th quintiles reflecting the spatial (among stations) and temporal (among years) variability. The predicted OC medians are shown for the REF (blue), NY (purple) and NY_DPH (red) simulations. The predicted primary OC is also shown (brown dashed line) and is similar for all simulations.

SOA mass is converted to organic carbon mass assuming that the OA / OC ratio is 2.1 (similar to previous GEOS-Chem studies, e.g., Pye and Seinfeld, 2010; Jo et al., 2013).

\subsubsection{Comparison with surface measurements}

Figure $4 \mathrm{a}$ shows the model evaluation over the continental USA with the monthly mean ground OC data from the IMPROVE network. The comparison shows that predicted OC is underestimated by $\sim 10 \%$ for the REF run. With the new wall-corrected yields (NY), the predicted OC concentrations are $35 \%$ higher than the observed ones, and these overpredictions can reach a factor of 2-3 at some locations. When the photolytic and heterogeneous losses of SOA are included (NY_DPH run), the model is in better agreement with observations for average OC concentrations (bias of $\sim 7 \%$ ) and slightly better spatiotemporal correlation $\left(R^{2}=0.49\right.$ vs. $0.45)$. Figure 5a shows that the NY_DPH simulation captures well the magnitude and seasonal variability in $\mathrm{OC} \mathrm{ob-}$ servations, which are characterized by $2-3$ times larger OC concentrations during summer than during winter. The posi- tive bias in NY_DPH seems to occur mainly during summer months (10-20\% in August) and could partially be due to evaporation of OC from IMPROVE summer samples during sampling and shipping, which was estimated to be $\sim 25 \%$ by Kim et al. (2015). The other model variants also capture relatively well the seasonal variability, but the absolute values are either severely underpredicted (REF) or overpredicted (NY). The comparison of surface concentrations could also suffer from uncertainties in the boundary layer parameterizations, though it should be noted that the GEOS-5 meteorological analysis were found to reproduce reasonably well (within $25 \%$ ) the boundary layer heights as compared to the CALIPSO data (Jordan et al., 2010).

The comparison over Europe with the EMEP data (Fig. 4b) shows a more severe model underestimation with a normalized mean bias of $-38 \%$ for the REF run and $-31 \%$ for the NY_DPH run. The correlation coefficient is low $\left(R^{2} \sim 0.17\right)$, possibly due to the comparison of different time periods (measurements 2002-2003). Figure 5b suggests that the observed OC seasonal cycle is very different in Europe than in the USA, with the highest OC concentrations occurring during winter vs. summer, respectively. Most of the model bias for Europe can be attributed to a severe underprediction of the primary OC during winter months in all model runs. These wintertime OC discrepancies are likely due to underestimated wood-burning contributions as discussed in previous studies (e.g., Denier van der Gon et al., 2015; Simpson et al., 2007).

Figure $4 \mathrm{c}$ also compares the predicted monthly mean SOA concentrations (averaged over 2005-2008) with the AMS measurements made at 20 locations worldwide (Zhang et al., 2007). Only background and rural sites were considered given the model coarse horizontal model resolution. Figure $4 \mathrm{c}$ suggests that the REF simulation is underpredicting SOA concentrations by on average $\sim 40 \%$ over all sites. Increased production in the NY simulation leads to a $23 \%$ average overprediction of surface SOA. The best agreement is obtained for simulations that accounted for both updated production yields and removal processes (NY_DPH) with a negative model average bias of $14 \%$. Given the coarse model resolution, the most meaningful comparison with the measurements is expected to be with the background sites (blue triangles) at which the NY_DPH simulations capture reasonably the observed SOA levels. Again the correlation coefficients for all simulations are low $\left(R^{2} \sim 0.1\right)$ due to differences in time periods.

\subsubsection{Comparison with aircraft vertical profiles}

Figure 6 compares the mean vertical profiles of OA measured during several aircraft campaigns and predicted by GEOS-Chem. Three of these campaigns are representative of remote conditions (ITOP, IMPEX, VOCALS-UK), whereas the other five were performed to study regional pollution or biomass burning plumes (EUCAARI, ARCTAS, Tex- 

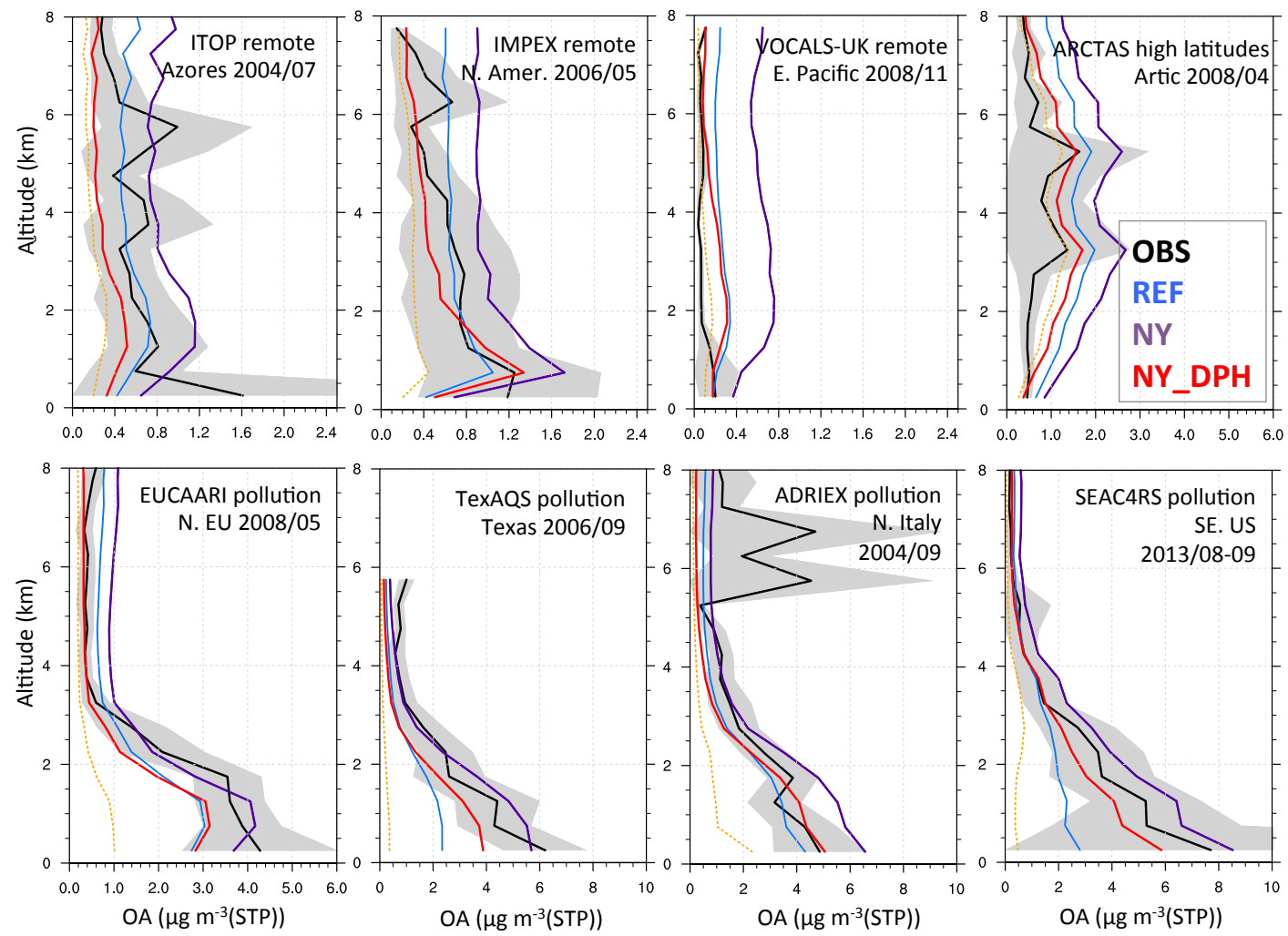

Figure 6. Comparison of mean OA vertical profiles $\left(\mu \mathrm{g} \mathrm{m}^{-3}(\mathrm{STP})\right.$ at $273.15 \mathrm{~K}$ and $\left.1013.25 \mathrm{hPa}\right)$ measured during recent aircraft field campaigns (see Table S5) with the corresponding GEOS-Chem predictions from three simulations including REF (blue), NY (purple) and NY_DPH (red). Concentrations of primary OC are also shown (dashed orange line) and are similar in all model runs. Flights in remote or high latitude (top row) and moderately polluted (bottom row) regions are shown. Variability around observed values (2 standard deviations) at each altitude are shown with shaded area. For ARCTAS, the observed OA concentrations above the 99th percentile, i.e., larger than $16 \mu \mathrm{g} \mathrm{m}^{-3}$ (STP), were filtered out to limit the influence of biomass burning plumes. For SEAC4RS the observations of acetonitrile were used to filter out fire plumes, and data above the 80 th percentile $(\sim 140 \mathrm{ppt})$ of observed acetonitrile concentrations were excluded. The model simulations are sampled for the year, month and locations of each aircraft campaign except for two campaigns including ITOP and ADRIEX for which average values between 2005 and 2008 are used for the month matching the field project.

AQS, ADRIEX, SEAC4RS). It should be kept in mind that the model resolution is too coarse to correctly represent typical biomass burning plume structures and spatial gradients. The base-case model (REF) typically underestimates observed OA concentrations in the lower troposphere and overestimates in the upper troposphere in most regions. This difficulty in capturing the vertical distribution of OA is particularly noticeable for the IMPEX and EUCAARI data. Increasing the SOA production (NY) leads to much larger concentrations at all altitudes, resulting sometimes in a better agreement with observations near the surface (SEAC4RS, TexAQS, EUCAARI) was well as often in a model overprediction of surface concentrations (ARCTAS, ADRIEX, VOCALS-UK). The overprediction of the upper-tropospheric OA concentrations is systematic in all environments for the NY run, suggesting that additional removal processes may be occurring. This overestimation in the free troposphere was seen in previous studies as well when the SOA production was artificially increased (e.g., Hodzic et al., 2010; Heald et al., 2011; Shrivastava et al., 2011). The model better captures the shape of the OA vertical profile when photolytic and heterogeneous removals are included. This improvement is seen for most campaigns. With the NY_DPH run, higher concentrations are simulated in the boundary layer than with the REF simulations reducing the gap with observations, while the model overprediction in the upper troposphere is reduced compared to the NY run. The globally averaged ratio between the predicted SOA by the updated NY_DPH and the default REF model simulations is also shown in Fig. 2, and it indicates that the updated SOA scheme leads up to a $50 \%$ increase in near-surface SOA concentrations and up to a $60 \%$ decrease in the upper troposphere. 


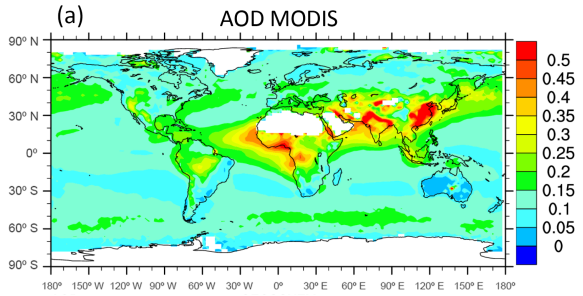

(b) AOD GEOS-Chem (NY_DPH)

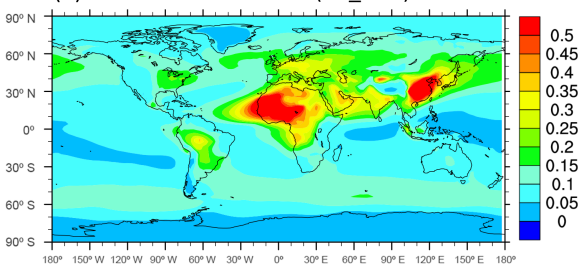

(c)
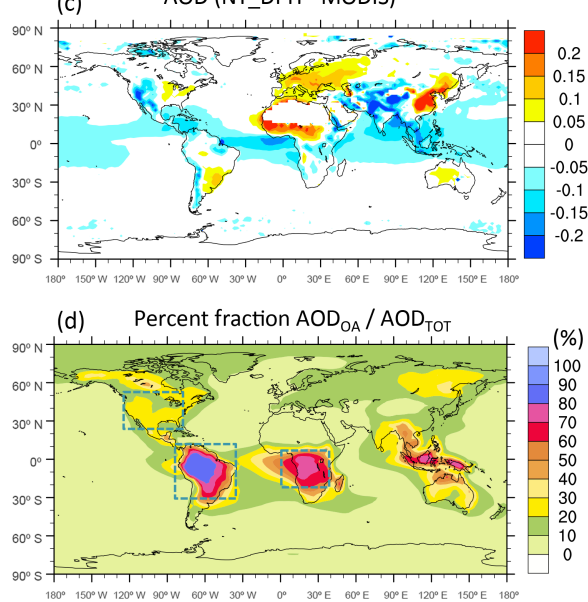

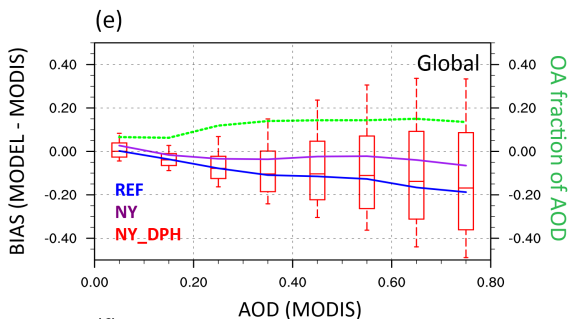

(f)
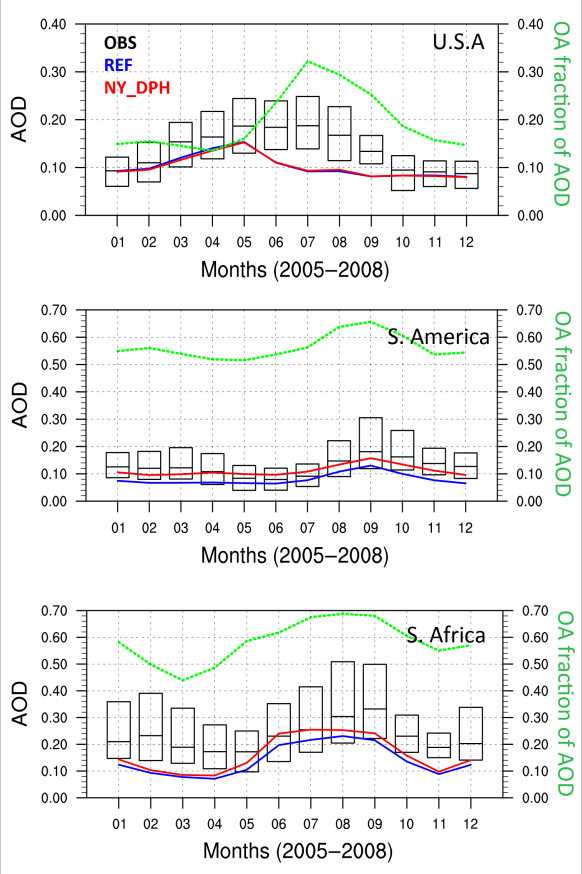

Figure 7. Comparison of 2005-2008 averaged AOD levels as measured by MODIS (Aqua and Terra) and predicted by the GEOS-Chem NY_DPH simulation. The difference (c) between modeled and observed AODs is also shown, only for days/locations when observations are available. The dependence of the model bias on the AOD levels is also shown (e). Panel (d) shows the contribution of organic aerosols to total modeled AOD for the NY_DPH simulations, which allows us to identify regions where AOD predictions are highly sensitive to SOA predictions. Panel (f) shows the predicted and observed 2005-2008 monthly average AOD in various regions shown in (d). The boxes show the observed medians, 25th and 75th quintiles reflecting the spatial (among grid boxes in the region) and temporal (among years) variability.

\subsubsection{Comparison with satellite aerosol optical depth (AOD) measurements}

Figure 7 compares AOD at $550 \mathrm{~nm}$ simulated by the GEOSChem base-case (REF) and modified (NY_DPH) runs with the corresponding retrievals from the MODIS (MODerate resolution Imaging Spectrometers) Terra and Aqua satellites between 2005 and 2008. The largest mean AOD levels ( $>0.5$ ) are observed over Northern Africa due to dust emissions and over China and India in relation to anthropogenic activities. As the AOD variable accounts for all aerosols including the aerosol water, its sensitivity to SOA parameterizations is only going to be significant over regions where SOA is the major contributor to the total aerosol load. Figure $7 \mathrm{~d}$ shows the contribution of $\mathrm{OA}$ to the simulated total AOD by the NY_DPH run. The predicted AOD is par- ticularly sensitive to organic aerosols with contribution of $>60 \%$ over the Amazon, South Africa and Southeast Asia. These regions are also strongly influenced by biomass burning and a large fraction of OA is likely from POA emissions. Over the continental USA and Europe, the sensitivity is somewhat lower with OA contribution of $10-30 \%$ to the calculated AOD. The relative OA contribution to AOD is increased by $5-10 \%$ in the NY_DPH simulation relative to the base-case run (not shown here). This increased OA contribution to the total aerosol load (predicted by NY_DPH) is consistent with the global AMS surface observations reported by Zhang et al. (2007) in which OA accounts for more than $35 \%$ of the submicron aerosol at the surface. Our results are also consistent with the modeling study by Kim et al. (2015) who found that OA contributed about $\sim 40 \%$ of the total AOD over the southeastern USA during the SEAC4RS field 
project. It should be noted that regions that are dominated by $\mathrm{OA}$ (contribution to AOD $>50 \%$ ) are not the ones displaying the largest biases in AOD, although the contribution of OA could be underpredicted.

The comparison of seasonal AOD cycles over the USA (Fig. 7f) shows a relatively small model bias during winter months and a large model underestimation in summer (up to $50 \%$ ). Even though the relative contribution of OA to the total AOD is higher during summer $25-35 \%$ (consistent with Zhang et al., 2007) the OA fraction is likely underestimated. The seasonal variability and aerosol load predicted by the NY_DPH run are particularly well captured over South America and are within a factor of 2 of observed AODs over central Africa.

\subsection{Global annual budgets}

Global 2005-2008 annual-average budgets showing the mass burden and source/sink terms for the combined gas- and particle-phase SOA system are presented in Table 5 and Fig. 8 for the REF, NY and NY_DPH simulations. We assess individual and combined effects of the various sink processes considered on global SOA burdens by examining diagnosed process lifetimes (see Table 6).

As expected, the SOA particle burden is largest in the NY simulation $(2.31 \mathrm{Tg})$, which is a factor of 2.6 higher than the corresponding burden in the REF simulation. This large increase is caused by two factors: (i) the increased production $\left(228 \mathrm{Tg} \mathrm{yr}^{-1}\right.$ vs. $\left.155 \mathrm{Tg} \mathrm{yr}^{-1}\right)$ and lower volatility $(43 \%$ vs. $14 \%$ net conversion of oxygenated gas-phase to particlephase VOCs) of biogenic SOA constituents in the NY simulation relative to the REF simulation and (ii) the additional source in the NY simulation of $27.7 \mathrm{Tg} \mathrm{yr}^{-1}$ oxygenated VOC gases from IVOC oxidation, which largely partition to the particle phase (net conversion of $>90 \%$ to particlephase) due to their low volatility (see Table 1). These two factors more than offset the decrease in SOA from traditional anthropogenic precursors (discussed in Sect. 3.2.1; see panel showing decrease in anthropogenic SOA in the NY simulation relative to the REF simulation in Fig. 1) and the lower biogenic SOA particle lifetimes in the NY simulation relative to the REF simulation.

For the REF and NY simulations (which have identical loss parameterizations), SOA removal is dominated by wet deposition (70-80\% of total sink), with dry deposition playing a minor role in determining the overall SOA removal lifetime. This is generally consistent with previous global model studies, which do not consider photochemical losses of organics or use $H^{\text {eff }}$ in the $10^{3}-10^{5} \mathrm{M} \mathrm{atm}^{-1}$ range (see, for example, the multi-model intercomparison by Tsigaridis et al., 2014). Comparing the NY_DPH simulation with the NY simulation shows that using the updated Henry's coefficients results in more efficient dry deposition of biogenic oxygenated VOC gases thereby shifting the balance between dry and wet deposition as the primary sink of these gases, and
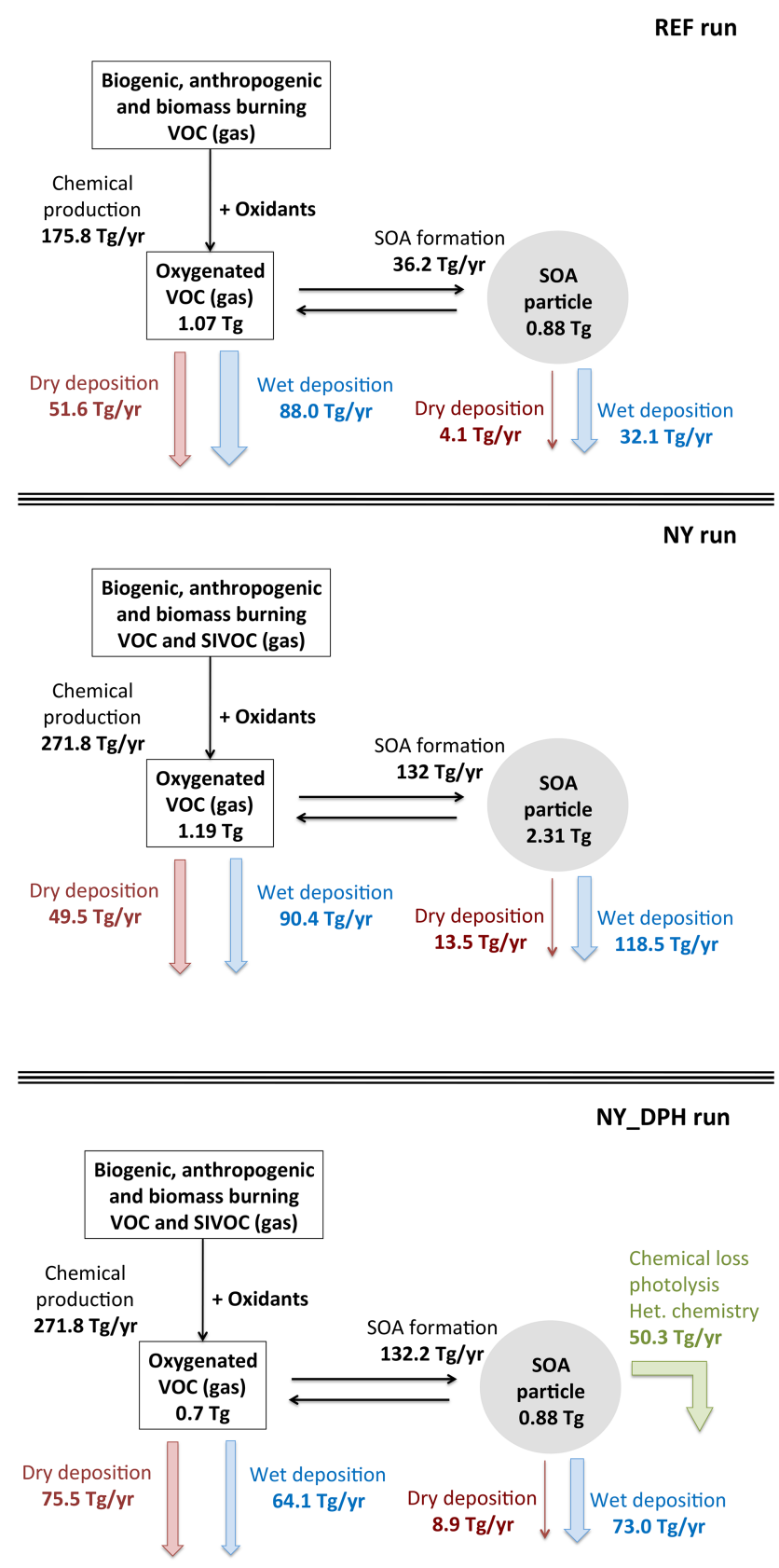

Figure 8. Global budgets (sources/sinks $\mathrm{Tg} \mathrm{yr}^{-1}$ and burden $\mathrm{Tg}$ ) of condensable secondary organic gas and particle compounds as predicted by the GEOS-Chem REF, NY and NY_DPH simulations for 2005-2008.

lowering the overall lifetime of both gas- and particle-phase constituents.

While the particle-phase production rate in the NY_DPH simulation is comparable to the production rate in the NY simulation, the overall particle-phase lifetime is significantly lower in the NY_DPH simulation due to the photolytic loss of particle-phase SOA at rates comparable to wet deposition rates. As a consequence, the particle-phase burden 
Table 5. Global annual-average budgets for organic gases and particles for the 4-year (2005-2008) period. VOC from anthropogenic, biomass burning (BB) and biogenic sources are indicated, as well as S/IVOC from anthropogenic and BB sources.

\begin{tabular}{|c|c|c|c|c|c|c|c|c|c|c|}
\hline $\begin{array}{l}\text { Sources of } \\
\text { oxygenated } \\
\text { species }\end{array}$ & $\begin{array}{r}\text { Gas } \\
\text { production } \\
\left(\mathrm{Tg} \mathrm{yr}^{-1}\right)\end{array}$ & $\begin{array}{r}\text { Gas } \\
\text { burden } \\
(\mathrm{Tg})\end{array}$ & $\begin{array}{r}\text { Gas dry } \\
\text { deposition } \\
\left(\mathrm{Tg} \mathrm{yr}^{-1}\right)\end{array}$ & $\begin{array}{r}\text { Gas wet } \\
\text { deposition } \\
\left(\mathrm{Tg} \mathrm{yr}^{-1}\right)\end{array}$ & $\begin{array}{l}\text { Net particle } \\
\text { production } \\
\quad\left(\mathrm{Tg} \mathrm{yr}^{-1}\right)\end{array}$ & $\begin{array}{l}\text { Particle } \\
\text { dry dep. } \\
\left(\mathrm{Tg} \mathrm{yr}^{-1}\right)\end{array}$ & $\begin{array}{r}\text { Particle } \\
\text { wet dep. } \\
\left(\mathrm{Tg} \mathrm{yr}^{-1}\right)\end{array}$ & $\begin{array}{r}\text { Photolytic/ } \\
\text { heterogeneous loss } \\
\left(\operatorname{Tg~yr}^{-1}\right)\end{array}$ & $\begin{array}{r}\text { Particle } \\
\text { burden } \\
(\mathrm{Tg})\end{array}$ & $\begin{array}{r}\text { Particle } \\
\text { lifetime } \\
\text { (days) }\end{array}$ \\
\hline \multicolumn{11}{|c|}{ REF run } \\
\hline Anthro. and BB VOC & 21.1 & 0.04 & 3.0 & 3.4 & 14.7 & 1.9 & 12.8 & 0 & 0.35 & 8.6 \\
\hline Biogenic VOC & 154.7 & 1.03 & 48.6 & 84.6 & 21.5 & 2.2 & 19.3 & 0 & 0.53 & 9.0 \\
\hline Total $^{\mathrm{b}}$ & 175.8 & 1.07 & 51.6 & 88.0 & 36.2 & 4.1 & 32.1 & 0 & 0.88 & \\
\hline Primary & & & & & Source: 56.4 & 9.9 & 46.5 & 0 & 0.94 & 6.1 \\
\hline \multicolumn{11}{|c|}{ NY run } \\
\hline Anthro. and BB VOC & 16.0 & 0.1 & 3.5 & 5.0 & 7.4 & 0.95 & 6.5 & 0 & 0.20 & 10 \\
\hline Biogenic VOC & 228.1 & 1.1 & 44.9 & 83.9 & 99.3 & 9.4 & 89.9 & 0 & 1.62 & 6 \\
\hline Anthro. and BB S/IVOC & 27.7 & 0.02 & 1.1 & 1.4 & 25.2 & 3.15 & 22.1 & 0 & 0.48 & 7 \\
\hline Total $^{\mathrm{b}}$ & 271.8 & 1.2 & 49.5 & 90.4 & 132 & 13.5 & 118.5 & 0 & 2.31 & \\
\hline Primary & & & & & Source: 56.4 & 9.9 & 46.5 & 0 & 0.94 & 6.1 \\
\hline \multicolumn{11}{|c|}{ NY_DPH run } \\
\hline Anthro. and BB VOC & 16.0 & 0.07 & 3.0 & 4.3 & 8.8 & 0.6 & 3.8 & 4.3 & 0.08 & 3.3 \\
\hline Biogenic VOC & 228.1 & 0.617 & 71.8 & 58.8 & 97.5 & 6.3 & 56.5 & 34.7 & 0.59 & 2.2 \\
\hline Anthro. and BB S/IVOC & 27.7 & 0.014 & 0.7 & 1.0 & 25.9 & 2.0 & 12.6 & 11.3 & 0.21 & 3.0 \\
\hline Total $^{\mathrm{b}}$ & 271.8 & 0.701 & 75.5 & 64.1 & 132.2 & 8.9 & 73.0 & 50.3 & 0.88 & \\
\hline Primary & & & & & Source: 56.4 & 9.9 & 46.5 & 0 & 0.94 & 6.1 \\
\hline
\end{tabular}

Table 6. Global annual-average lifetimes for organic gases and particles for the 4-year (2005-2008) period. VOC from anthropogenic, biomass burning (BB) and biogenic sources are indicated, as well as S/IVOC from anthropogenic and BB sources.

\begin{tabular}{|c|c|c|c|c|c|c|}
\hline $\begin{array}{l}\text { Sources of } \\
\text { oxygenated } \\
\text { species }\end{array}$ & $\begin{array}{r}\text { Gas dry } \\
\text { deposition } \\
\text { lifetime (days) }\end{array}$ & $\begin{array}{r}\text { Gas wet } \\
\text { deposition } \\
\text { lifetime (days) }\end{array}$ & $\begin{array}{r}\text { Particle dry } \\
\text { deposition lifetime } \\
\text { (days) }\end{array}$ & $\begin{array}{r}\text { Particle wet } \\
\text { deposition lifetime } \\
\text { (days) }\end{array}$ & $\begin{array}{r}\text { Particle } \\
\text { chem loss } \\
\text { lifetime (days) }\end{array}$ & $\begin{array}{r}\text { Particle } \\
\text { overall lifetime } \\
\text { (days) }\end{array}$ \\
\hline \multicolumn{7}{|c|}{ REF simulation } \\
\hline Anthro. and BB VOC & 5.0 & 4.4 & 66.5 & 9.9 & NA & 8.6 \\
\hline Biogenic VOC & 7.7 & 4.4 & 87.4 & 10.1 & NA & 9.0 \\
\hline \multicolumn{7}{|c|}{ NY simulation } \\
\hline Anthro. and BB VOC & 9.4 & 6.8 & 78.2 & 11.5 & NA & 10.0 \\
\hline Biogenic VOC & 8.7 & 4.7 & 63.1 & 6.6 & NA & 6.0 \\
\hline Anthro. and BB S/IVOC & 7.2 & 5.4 & 55.7 & 8.0 & NA & 7.0 \\
\hline \multicolumn{7}{|c|}{ NY_DPH simulation } \\
\hline Anthro. and BB VOC & 8.5 & 6.1 & 43.3 & 7.4 & 6.6 & 3.3 \\
\hline Biogenic VOC & 3.1 & 3.8 & 34.4 & 3.8 & 6.2 & 2.2 \\
\hline Anthro. and BB S/IVOC & 6.8 & 5.1 & 38.4 & 6.1 & 6.8 & 3.0 \\
\hline
\end{tabular}

in the NY_DPH simulation $(0.88 \mathrm{Tg})$ is significantly lower than in the NY simulation $(2.31 \mathrm{Tg})$. It is also worth noting that global-average particle-phase burdens in the REF and NY_DPH simulations are comparable. However, the NY_DPH simulation presents a far more dynamic picture, with stronger production rates and more efficient removal leading to very different, and likely more realistic, horizontal and vertical spatial patterns in the SOA distribution relative to the REF simulation as discussed in the previous sections.

Our best estimate of the global SOA particle-phase production rate is $132.2 \mathrm{Tg} \mathrm{yr}^{-1}$, which is remarkably similar to the central estimate of $140 \mathrm{Tg} \mathrm{yr}^{-1}$ derived by Spracklen et al. (2011) using a top-down approach constrained by a global data set of surface AMS measurements (Fig. 9). Spracklen et al. (2011) further estimate that a large fraction $\left(100 \mathrm{Tg} \mathrm{yr}^{-1}\right)$ is anthropogenically controlled, but from non-fossil sources of carbon. While we cannot estimate an equivalent anthropogenically controlled source fraction in our study, our estimate of the biogenic source $\left(97.5 \mathrm{Tg} \mathrm{yr}^{-1}\right)$ is also consistent with the Spracklen et al. (2011) estimate of the non-fossil source magnitude. It is worth noting, however, that our simulated global burden of $0.88 \mathrm{Tg}$ in the NY_DPH simulation is about a factor of 2 lower than in the Spracklen et al. (2011) study because of the shorter aerosol lifetimes due to the inclusion of particle-phase photolysis in our simulations. 


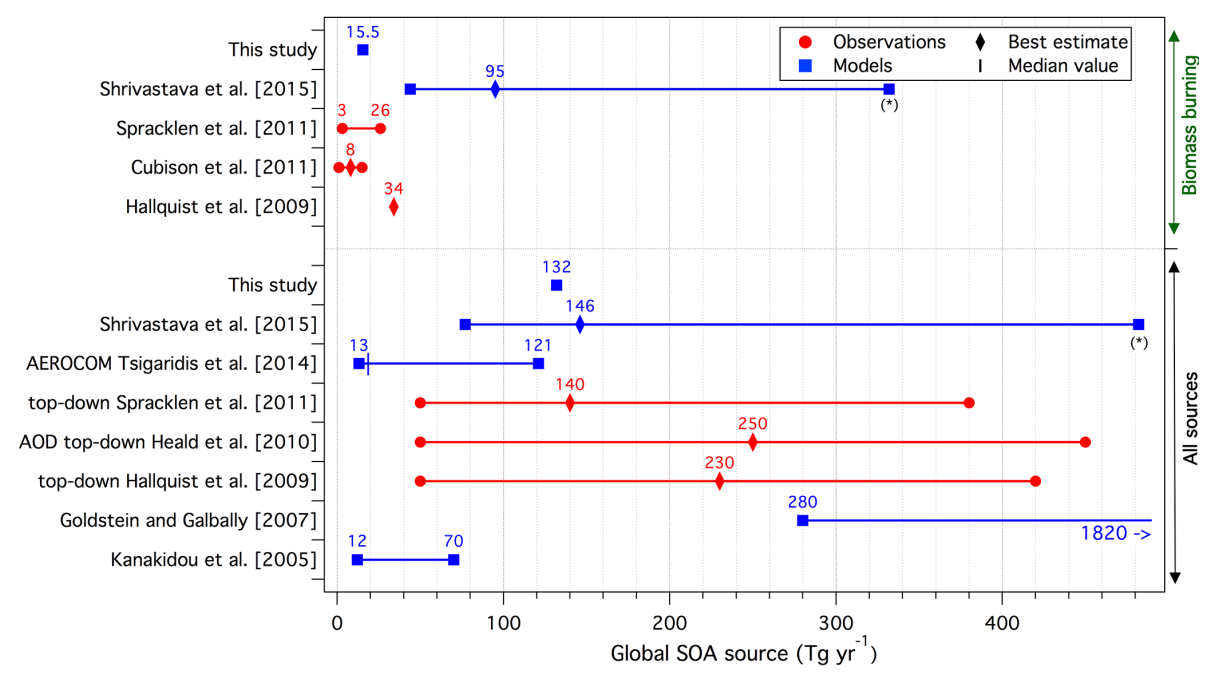

Figure 9. Global SOA particle-phase source $\left(\mathrm{Tg} g r^{-1}\right)$ as predicted in this study (NY_DPH) and as reported by previous studies. SOA production from all sources (anthropogenic, biomass burning, biofuel and biogenic) as well as from biomass burning alone is shown. ${ }^{*}$ The upper values shown for Shrivastava et al. (2015) are an absolute upper limit testing the sensitivity of SOA to the fragmentation of oxidized organic gases. In this case the fragmentation is omitted, leading to unrealistically high SOA production compared to the best-estimate run in which the fragmentational loss represents $\sim 270 \mathrm{Tg} \mathrm{yr}^{-1}$.

Our best estimate of the particle-phase SOA source is also a factor of 3-4 higher than the central estimate from the AeroCom Phase II multi-model intercomparison exercise (Tsigaridis et al., 2014) though our calculated global burden is comparable due to the corresponding shorter aerosol lifetimes in our NY_DPH simulation. By contrast, our best source estimate is about a factor of 2 lower than the upper limit estimate of $250 \mathrm{Tg} \mathrm{yr}^{-1}$ (assuming a $2: 1 \mathrm{OA} / \mathrm{OC}$ mass ratio and the POA production of $\sim 50 \mathrm{Tg} \mathrm{yr}^{-1}$ estimated for the study period) derived by Heald et al. (2010) using continental AOD retrievals from MISR. This is despite the fact that the aerosol lifetimes in the Heald et al. (2010) study are about a factor of 2 lower than in the NY_DPH simulation. While we cannot compare directly to their study, we speculate that a portion of this apparent discrepancy is due to the simplifying assumption by Heald et al. (2010) that the scale height of the atmosphere $(\sim 7.5 \mathrm{~km})$ can be used to characterize the exponentially decreasing vertical profile of OA. This differs significantly from the much steeper vertical gradient, corresponding to a scale height of about $2.5 \mathrm{~km}$, in the NY_DPH simulation (see Fig. 2), which provides the best match to aircraft vertical profiles as discussed in Sect. 3.2.2. As noted by Heald et al. (2010), for a given column loading of dry aerosol mass, AOD is higher when a greater fraction of the aerosol mass is near the surface due to increased water uptake. As a consequence, a lower source strength can be consistent with measured AOD when a greater fraction of aerosol mass is near the surface.

We also note that the contribution of the biomass burning source to SOA formation in the updated NY_DPH model is $\sim 15.5 \mathrm{Tg} \mathrm{yr}^{-1}\left(14 \mathrm{Tg} \mathrm{yr}^{-1}\right.$ produced from S/IVOC pre- cursors and $\sim 1.5 \mathrm{Tg} \mathrm{yr}^{-1}$ from aromatics). Compared to estimates from the earlier field campaign analysis (Fig. 9), our results are within the range of values reported by Cubison et al. (2011), who suggested the biomass burning contribution to SOA of $\sim 8( \pm 7) \mathrm{Tg} \mathrm{yr}^{-1}$, and are consistent with Jolleys et al. (2012), who found a small production of organic aerosols in biomass burning plumes. Compared to recent global modeling studies (Fig. 9), our estimates are much lower than those reported by Shrivastava et al. (2015) in which SOA production is dominated by biomass burning ( $\sim 95 \mathrm{Tg} \mathrm{yr}^{-1}$ of SOA is formed from biomass burning for their best estimate). Our results are comparable to those of Spracklen et al. (2011), who estimated the biomass burning SOA source of $3 \mathrm{Tg} \mathrm{yr}^{-1}$ from direct emissions of its precursors and an additional $23 \mathrm{Tg} \mathrm{yr}^{-1}$ from conversion of POA (mostly from biomass burning). The anthropogenic SOA source from traditional aromatic precursors present in the emission inventories is $\sim 7 \mathrm{Tg} \mathrm{gr}^{-1}$ in the updated NY_DPH model and is comparable to estimates provided by previous studies, i.e., $10 \mathrm{Tg} \mathrm{yr}^{-1}$ (Spracklen et al., 2011) and 13.5 $\mathrm{Tg} \mathrm{yr}^{-1}$ (de Gouw and Jimenez, 2009).

\subsection{Atmospheric and societal implications}

\subsubsection{Effect on health exposure}

Changes in SOA spatial distribution resulting from the updated representation of production and removals rates were discussed in Sect. 3.1. On a global-average basis, Fig. 2 shows that surface SOA concentrations increase from $\sim 0.25 \mu \mathrm{g} \mathrm{m}^{-3}$ in the REF simulation to $\sim 0.5 \mu \mathrm{g} \mathrm{m}^{-3}$ in the NY_DPH simulation. From a human health exposure 
perspective, it is important to assess the extent to which spatial changes in simulated SOA concentrations overlap with the spatial distribution of population and how these changes translate into changes in estimated health impacts. A detailed analysis of health impacts is beyond the scope of this paper and would require higher resolution model predictions. Here, we focus on a simple metric to characterize human-health-relevant changes in surface SOA concentrations and identify broad regions where these changes could have an impact. For each simulation, we calculate the global-average population-weighted surface SOA concentration [PWSOA] $]_{\text {surf }}$ by combining 2005-2008 annualaverage modeled surface SOA fields with gridded population data for 2005 (http://sedac.ciesin.columbia.edu). We find that $[\mathrm{PWSOA}]_{\text {surf }}$ for the NY_DPH simulation is $2.6 \mu \mathrm{g} \mathrm{m} \mathrm{m}^{-3}$ which is a factor of 2 higher than the corresponding metric for the REF simulation. Figure 10 shows the contribution of individual model grid cells to $[\mathrm{PWSOA}]_{\text {surf }}$ for the NY_DPH simulation, as well as the contribution to changes in $[\mathrm{PWSOA}]_{\text {surf }}$ between the NY_DPH and REF simulations. Comparing the top panel of Fig. 10 with Fig. 3b shows that while highest-boundary-layer SOA concentrations are found in tropical Africa and South America, high population regions in East and Southeast Asia contribute the most to $[\mathrm{PWSOA}]_{\text {surf. These are also the regions that contribute }}$ the most to changes in $[\mathrm{PWSOA}]_{\text {surf }}$ between the NY_DPH and REF simulations.

Recent analysis by Lim et al. (2012) and future projections by Lelieveld et al. (2015) suggest that current and future impacts of particulate pollution on human health are and will be significant. The simple analysis presented here suggests the need for a more in-depth study to evaluate the contribution of SOA to PM-related human health effects in order to better understand how SOA precursor controls can serve to mitigate these negative effects.

\subsubsection{Direct radiative effect (DRE)}

The clear-sky DRE of SOA at the top of the atmosphere is estimated for the GEOS-Chem NY_DPH simulation to assess the potential radiative effects of the modeled updates in production and removal of organic aerosols (Fig. 11). DRE is calculated offline from the GEOS-Chem model outputs using the rapid radiative transfer model for global climate models (RRTMG; Iacono et al., 2008). We use 14 wavelength bands ranging from 300 to $8021 \mathrm{~nm}$. RRTMG uses the AOD, single scattering albedo and asymmetry parameter for each aerosol type to determine aerosol impacts on radiation. Furthermore, RRTMG requires surface albedo inputs, and these inputs are from MERRA reanalysis (Rienecker et al., 2011). Aerosol optical properties at a specific wavelength are calculated from the GEOS-Chem output using FlexAOD (Curci et al., 2015), which is based on the Mie theory (Wiscombe, 1980). SOA is assumed to follow log-normal distributions with microphysical properties from OPAC data set

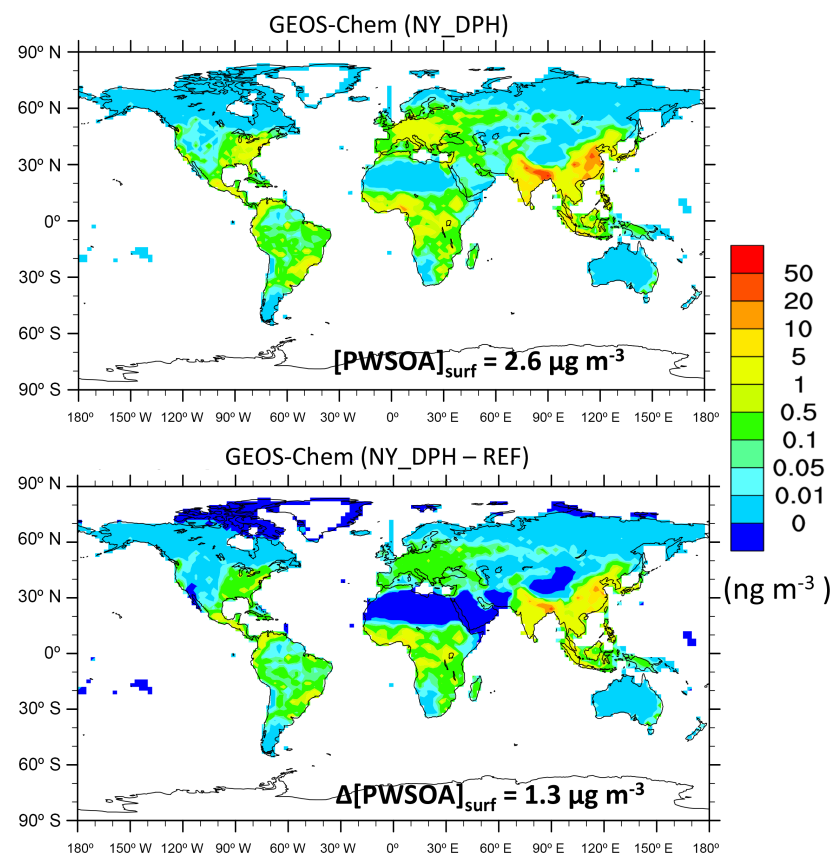

Figure 10. Contribution of individual models grid cells to global population-weighted surface SOA concentration [PWSOA $]_{\text {surf }}$ in the NY_DPH simulation (top) and to changes in [PWSOA $]_{\text {surf }}$ between the NY_DPH and REF simulation. The total PWSOA is obtained by summing up the individual grid cell contributions shown in the figure.

(Hess et al., 1998). The meteorological input data needed for FlexAOD are from GEOS-5 assimilated meteorological data.

The area-weighted global mean clear-sky DRE value is $-0.33 \mathrm{~W} \mathrm{~m}^{-2}$ in the updated NY_DPH simulation, which has a fairly comparable cooling effect at the top of the Earth's atmosphere to the one found for the REF simulation of $-0.37 \mathrm{~W} \mathrm{~m}^{-2}$. Although the global value is similar between the two runs, the spatial distribution is very different. In the NY_DPH simulation, DRE ranges from -0.01 to $-0.1 \mathrm{~W} \mathrm{~m}^{-2}$ over the background and to $-0.2 \mathrm{~W} \mathrm{~m}^{-2}$ over the outflow oceanic regions, from -0.5 to $-1 \mathrm{~W} \mathrm{~m}^{-2}$ over the continental USA and Europe and from -2 to $-5 \mathrm{~W} \mathrm{~m}^{-2}$ over the SOA source regions including South America, central and South Africa, Southeast Asia and southeastern USA. Compared to the REF simulation, DRE is significantly increased over the source regions and decreased over the remote regions, which is consistent with a stronger SOA production and a shorter SOA lifetime in the NY_DPH simulation as previously discussed. These differences are expected to modify atmospheric stability and affect cloud formation (IPCC, Forster et al., 2007). The estimated DRE associated with SOA $\left(-0.33 \mathrm{~W} \mathrm{~m}^{-2}\right.$ in NY_DPH) is within the range of recently reported values of $-0.26 \mathrm{~W} \mathrm{~m}^{-2}$ (Spracklen et al., 2011), $-0.28 \mathrm{~W} \mathrm{~m}^{-2}$ (Jo et al., 2013), -0.5 and $-0.26 \mathrm{~W} \mathrm{~m}^{-2}$ (Shrivastava et al., 2015). The estimated DRE is larger than in other studies, i.e., $-0.94 \mathrm{~W} \mathrm{~m}^{-2}$ (NY simula- 


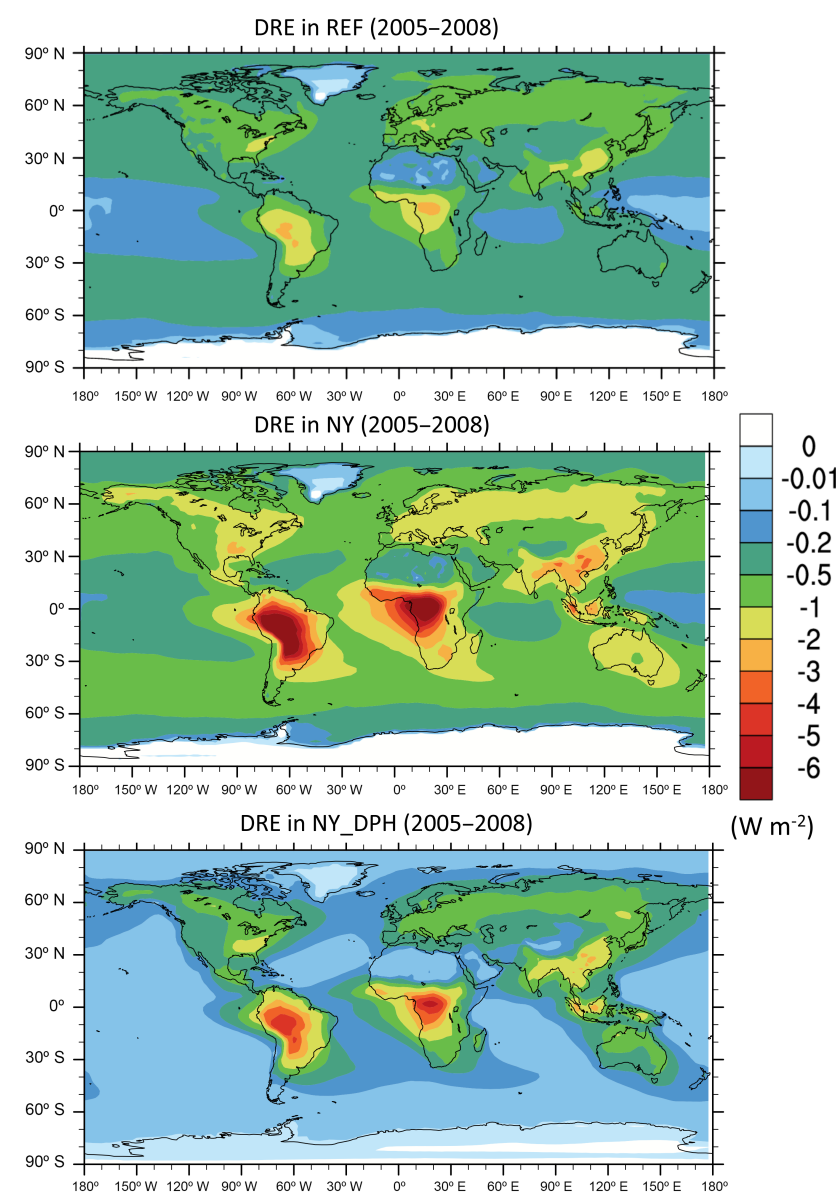

Figure 11. Simulated clear-sky SOA direct radiative effect (DRE) at the top of the atmosphere for the REF (upper), NY (middle) and NY_DPH runs (bottom).

tion), when only the updates to the production rates are considered. These values also suggest that additional removals are likely occurring within the entire tropospheric column.

\section{Conclusions}

Current global models do not reproduce important features of the observed OA distribution, particularly with regards to the relative gradient in SOA concentrations between the boundary layer and the free troposphere. Here, we have presented a revised picture of atmospheric SOA that involves stronger production rates and more efficient sinks that were implemented within the GEOS-Chem model. Together, these updates help overcome some of the limitations that current models have in simulating tropospheric SOA.

SOA production with new wall-corrected yields and emissions of semi-volatile and intermediate volatility organic species is substantially increased relative to the default GEOS-Chem simulation. Our best estimate of the global SOA particle-phase production rate is $132.2 \mathrm{Tg} \mathrm{yr}^{-1}$, which is remarkably similar to the central estimate of $140 \mathrm{Tg} \mathrm{yr}^{-1}$ derived by Spracklen et al. (2011) using a top-down approach constrained by a global data set of surface AMS measurements. The largest contribution to SOA production is from biogenic sources $\left(\sim 74 \%, 97.5 \mathrm{Tg} \mathrm{yr}^{-1}\right)$ with the remainder from anthropogenic and biofuel sources $(\sim 15 \%$, $\sim 13 \mathrm{Tg} \mathrm{yr}^{-1}$ from S/IVOC precursors and $\sim 7 \mathrm{Tg} \mathrm{yr}^{-1}$ from aromatics) and biomass burning sources $\left(\sim 11 \%, 13 \mathrm{Tg} \mathrm{yr}^{-1}\right.$ from S/IVOC precursors and $\sim 1.5 \mathrm{Tg} \mathrm{yr}^{-1}$ from aromatics). However, stronger production rates alone lead to an overprediction of the surface SOA concentrations relative to measurements from the AMS global network data and to an accumulation of SOA in the upper troposphere, which is not supported by vertical OA profiles measured by recent aircraft studies. The corresponding global SOA burden is $2.31 \mathrm{Tg}$ and the corresponding DRE at top of the atmosphere is $-0.94 \mathrm{~W} \mathrm{~m}^{-2}$, which is larger than in previous studies.

The inclusion of new and updated removal processes substantially reduces OA concentrations near the surface and in the free troposphere and generally leads to an improved agreement with measured vertical profiles from aircraft campaigns (although data are still too sparse to allow for a definitive conclusion at this point). We find that photolytic removal could account for $\sim 38 \%$ of the direct removal of the particle-phase SOA and serve as an important loss mechanism in the free troposphere where wet and dry deposition of $\mathrm{OA}$ is less efficient. The simulated global OA burden by the updated GEOS-Chem model $(0.88 \mathrm{Tg})$ is similar to the basecase run $(0.88 \mathrm{Tg})$ as well as to the central estimate simulated by the AeroCom Phase II models (Tsigaridis et al., 2014). Thus, our analysis suggests that the suite of AeroCom models likely underestimate SOA production rates and overestimate SOA lifetimes.

In the revised model with both updated sinks and sources, near-surface SOA concentrations (global averaged) are increased by up to $50 \%$ (within the first kilometer), whereas the upper-tropospheric concentrations are decreased by up to $60 \%$. One implication of this change is that the new model yields a population-weighted global mean SOA concentration that is twice as large as the base model, suggesting the need for a revaluation of human health impacts from ambient OA pollution. Changes in the clear-sky DREs at the top of the atmosphere are not substantial in terms of global averaged values with $-0.33 \mathrm{~W} \mathrm{~m}^{-2}$ for the updated simulation; however, the spatial distribution is very different, which could lead to changes in local climate impacts.

We have shown that the combination of missing precursor emissions, new production rates and removal processes leads to qualitative (and sometimes quantitative) improvements in simulating SOA, especially in terms of the vertical OA distribution. While initial comparisons with the limited available measurements are encouraging, uncertainties remain in the proposed source and sink parameterizations. One should keep in mind that the proposed VBS parameterization for the VOCs are derived from empirical fitting of laboratory 
experiments, which are performed on individual precursors and are highly dependent on experimental conditions. Further work is thus needed to fully understand the limitations associated with the use of the chamber-based SOA yields available for a small subset of surrogate precursors in 3-D models to represent complex atmospheric mixtures and ambient conditions. Although we have considerably improved the emissions of SOA precursors for the purpose of this study by adding S/IVOC emissions, we note that large uncertainties remain in emission inventories of biogenic and anthropogenic precursors (Goldstein and Galbally, 2007). We also recognize that our study has accounted for a subset of known SOA formation pathways, leaving out in particular the potentially important aqueous-phase formation of SOA in clouds droplets and wet particles (e.g., Ervens et al., 2011; Knote et al., 2014) or condensed-phase processes that lead to the formation of low-volatility compounds (e.g., Shiraiwa et al., 2013). Another important uncertainty pertains to SOA photolysis rates. To the extent that atmospheric SOA photolysis rates seem to be in the lower range of estimates reported from limited laboratory studies, SOA production rates may need to be higher to explain the observed SOA distribution. An important next step therefore is to reconcile laboratory and theoretical estimates of SOA photolysis rates. More field measurements are also needed to better characterize and evaluate boundary layer vs. free troposphere gradients in various source regions and in the remote atmosphere to further test our hypothesis.

\section{Data availability}

The following data has been used for this study: GEOSChem model (Harvard, 2015), IMPROVE data (EPA, 2015), EMEP data (NILU, 2015), AMS data (AMS, 2015), SEAC4RS data (NASA, 2015), gridded population data for 2005 (SEDAC, 2015) and the photolysis model TUV (NCAR, 2015).

\section{The Supplement related to this article is available online at doi:10.5194/acp-16-7917-2016-supplement.}

Acknowledgements. The authors thank Shantanu Jathar (Colorado State University) for helpful discussions on the emissions, Eric Apel (NCAR) for discussion on acetonitrile data, Pengfei Yu (University of Colorado) for assistance with the AMS data extraction, Christoph Knote (LMU) for providing the analysis tools used SI Annex-2 and Louisa Emmons and Pablo Saide (NCAR) for the NCAR internal review of our manuscript. This research was supported by the National Center for Atmospheric Research, which is operated by the University Corporation for Atmospheric Research on behalf of the National Science Foundation. We would like to acknowledge high-performance computing support from
Yellowstone provided by NCAR's Computational and Information Systems Laboratory. Alma Hodzic was supported by EPA STAR 83587701-0 and NASA NNX15AE38G, and Jose L. Jimenez was supported by EPA STAR 83587701-0 and NASA NNX15AH33A.

Disclaimer. This paper has not been formally reviewed by EPA. The views expressed in this document are solely those of the authors and do not necessarily reflect those of the Agency.

Edited by: R. MacKenzie

\section{References}

Ahmadov, R., McKeen, S. A., Robinson, A. L., Bahreini, R., Middlebrook, A. M., de Gouw, J. A., Meagher, J., Hsie, E. Y., Edgerton, E., Shaw, S., and Trainer, M.: A volatility basis set model for summertime secondary organic aerosols over the eastern United States in 2006, J. Geophys. Res., 117, D06301, doi:10.1029/2011JD016831, 2012.

AMS: Aerosol mass spectrometry, Global database, available at: https://sites.google.com/site/amsglobaldatabase/, last access: 1 March 2015.

Arellano Jr., A. F., Kasibhatla, P. S., Giglio, L., van der Werf, G. R., Randerson, J. T., and Collatz, G. J.: Time-dependent inversion estimates of global biomass-burning $\mathrm{CO}$ emissions using Measurement of Pollution in the Troposphere (MOPITT) measurements, J. Geophys. Res., 111, D09303, doi:10.1029/2005JD006613, 2006.

Aumont, B., Szopa, S., and Madronich, S.: Modelling the evolution of organic carbon during its gas-phase tropospheric oxidation: development of an explicit model based on a self generating approach, Atmos. Chem. Phys., 5, 2497-2517, doi:10.5194/acp-52497-2005, 2005.

Bessagnet, B., Seigneur, C., and Menut, L.: Impact of dry deposition of semi-volatile organic compounds on secondary organic aerosols, Atmos. Environ., 44, 1781-1787, 2010.

Bey, I., Jacob, D. J., Yantosca, R. M., and Logan, J. A.: Global modeling of tropospheric chemistry with assimilated meteorology e model description and evaluation, J Geophys. Res., 106, 23073 23095, 2011

Bond, T. C., Bhardwaj, E., Dong, R., Jogani, R., Jung, S., Roden, C., Streets, D. G., and Trautmann, N. M.: Historical emissions of black and organic carbon aerosol from energy-related combustion, 1850-2000, Global Biogeochem. Cy., 21, GB2018, doi:10.1029/2006GB002840, 2007.

Cappa, C. D. and Wilson, K. R.: Multi-generation gas-phase oxidation, equilibrium partitioning, and the formation and evolution of secondary organic aerosol, Atmos. Chem. Phys., 12, 9505-9528, doi:10.5194/acp-12-9505-2012, 2012.

Cappa, C. D., Jathar, S. H., Kleeman, M. J., Docherty, K. S., Jimenez, J. L., Seinfeld, J. H., and Wexler, A. S.: Simulating secondary organic aerosol in a regional air quality model using the statistical oxidation model - Part 2: Assessing the influence of vapor wall losses, Atmos. Chem. Phys., 16, 3041-3059, doi:10.5194/acp-16-3041-2016, 2016.

Canagaratna, M. R., Jayne, J. T., Jimenez, J. L., Allan, J. D., Alfarra, M. R., Zhang, Q., Onasch, T. B., Drewnick, F., Coe, H., Middlebrook, A., Delia, A., Williams, L. R., Trimborn, A. M., 
Northway, M. J., DeCarlo, P. F., Kolb, C. E., Davidovits, P., and Worsnop, D. R.: Chemical and microphysical characterization of ambient aerosols with the aerodyne aerosol mass spectrometer, Mass Spectrom. Rev., 26, 185-222, doi:10.1002/mas.20115, 2007.

Chung, S. and Seinfeld, J.: Global distribution and climate forcing of carbonaceous aerosols, J. Geophys. Res., 107, 4407, doi:10.1029/2001JD001397, 2002.

Cubison, M. J., Ortega, A. M., Hayes, P. L., Farmer, D. K., Day, D., Lechner, M. J., Brune, W. H., Apel, E., Diskin, G. S., Fisher, J. A., Fuelberg, H. E., Hecobian, A., Knapp, D. J., Mikoviny, T., Riemer, D., Sachse, G. W., Sessions, W., Weber, R. J., Weinheimer, A. J., Wisthaler, A., and Jimenez, J. L.: Effects of aging on organic aerosol from open biomass burning smoke in aircraft and laboratory studies, Atmos. Chem. Phys., 11, 12049-12064, doi:10.5194/acp-11-12049-2011, 2011.

Curci, G., Hogrefe, C., Bianconi, R., Im, U., Balzarini, A., Baró, R., Brunner, D., Forkel, R., Giordano, L., Hirtl, M., Honzak, L., Jiménez-Guerrero, P., Knote, C., Langer, M., Makar, P. A., Pirovano, G., Pérez, J. L., San José, R., Syrakov, D., Tuccella, P., Werhahn, J., Wolke, R., Žabkar, R., Zhang, J., and Galmarini, S.: Uncertainties of simulated aerosol optical properties induced by assumptions on aerosol physical and chemical properties: An AQMEII-2 perspective, Atmos. Environ., 115, 541-552, 2015.

de Gouw, J. A. and Lovejoy, E. R.: Reactive uptake of ozone by liquid organic compounds, Geophys. Res. Lett., 25, 931-934, 1998.

de Gouw, J. A. and Jimenez, J. L.: Organic aerosols in the Earth's atmosphere, Environ. Sci. Technol., 43, 7614-7618, doi:10.1021/es9006004, 2009.

Denier van der Gon, H. A. C., Bergström, R., Fountoukis, C., Johansson, C., Pandis, S. N., Simpson, D., and Visschedijk, A. J. H.: Particulate emissions from residential wood combustion in Europe - revised estimates and an evaluation, Atmos. Chem. Phys., 15, 6503-6519, doi:10.5194/acp-15-6503-2015, 2015.

Dzepina, K., Cappa, C. D., Volkamer, R. M., Madronich, S., DeCarlo, P. F., Zaveri, R. A., and Jimenez, J. L.: Modeling the Multiday Evolution and Aging of Secondary Organic Aerosol During MILAGRO 2006, Environ. Sci. Technol., 45, 3496-3503, doi:10.1021/es103186f, 2011.

EPA: IMPROVE data, available at: http://aqsdr1.epa.gov/aqsweb/ aqstmp/airdata/download_files.html, last access: 1 March 2015.

Epstein, S. A., Riipinen, I., and Donahue, N. M.: A Semiempirical Correlation between Enthalpy of Vaporization and Saturation Concentration for Organic Aerosol, Environ. Sci. Technol., 44, 743-748, doi:10.1021/es902497z, 2010.

Epstein, S. A., Blair, S. L., and Nizkorodov, S. A.: Direct Photolysis of $\alpha$-Pinene Ozonolysis Secondary Organic Aerosol: Effect on Particle Mass and Peroxide Content, Environ. Sci. Technol., 48, 11251-11258, doi:10.1021/es502350u, 2014.

Ervens, B., Turpin, B. J., and Weber, R. J.: Secondary organic aerosol formation in cloud droplets and aqueous particles (aqSOA): a review of laboratory, field and model studies, Atmos. Chem. Phys., 11, 11069-11102, doi:10.5194/acp-1111069-2011, 2011.

Farina, S. C., Adams, P. J., and Pandis, S. N.: Modeling global secondary organic aerosol formation and processing with the volatility basis set: implications for anthropogenic secondary organic aerosol, J. Geophys. Res., 115, D09202, doi:10.1029/2009JD013046, 2010.
Farmer, Q., Chen, J. R., Kimmel, K. S., Docherty, E., Nemitz, P. A., Artaxo, C. D., Cappa, S. T., Martin, S. T., and Jimenez, J. L.: Chemically-resolved particle fluxes over tropical and temperate forests, Aerosol Sci. Tech., 47, 818-830, doi:10.1080/02786826.2013.791022, 2013.

Forster, P. V., Ramaswamy, P., Artaxo, T., Berntsen, R., Betts, D.W., Fahey, J., Haywood, J., Lean, D. C., Lowe, G., Myhre, J., Nganga, R., Prinn, G., Raga, M. S., and Dorland, R. V.: Changes in Atmospheric Constituents and in Radiative Forcing. Cambridge University Press, United Kingdom and New York, NY, USA, 2007.

George, I. J. and Abbatt, J. P. D.: Chemical evolution of secondary organic aerosol from $\mathrm{OH}$-initiated heterogeneous oxidation, Atmos. Chem. Phys., 10, 5551-5563, doi:10.5194/acp-10-55512010, 2010.

Gentner, D. R., Isaacman, G., Worton, D. R., Chan, A. W. H., Dallmann, T. R., Davis, L., Liu, S., Day, D. A., Russell, L. M., Wilson, K. R., Weber, R., Guha, A., Harley, R. A., and Goldstein, A. H.: Elucidating secondary organic aerosol from diesel and gasoline vehicles through detailed characterization of organic carbon emissions, P. Natl. Acad. Sci. USA, 109, 18318-18323, 2012.

Goldstein, A. H. and Galbally, I. E.: Known and unexplored organic constituents in the earth's atmosphere, Environ. Sci. Technol., 41, 1514-1521, 2007.

Guenther, A. B., Jiang, X., Heald, C. L., Sakulyanontvittaya, T., Duhl, T., Emmons, L. K., and Wang, X.: The Model of Emissions of Gases and Aerosols from Nature version 2.1 (MEGAN2.1): an extended and updated framework for modeling biogenic emissions, Geosci. Model Dev., 5, 1471-1492, doi:10.5194/gmd-51471-2012, 2012.

Harvard: GEOS-Chem Model, available at: http://acmg.seas. harvard.edu/geos/index.html, last access: January 2015.

Heald, C. L., Ridley, D. A., Kreidenweis, S. M., and Drury, E. E.: Satellite observations cap the atmospheric organic aerosol budget, Geophys. Res. Lett., 37, L24808, doi:10.1029/2010GL045095, 2010.

Heald, C. L., Coe, H., Jimenez, J. L., Weber, R. J., Bahreini, R., Middlebrook, A. M., Russell, L. M., Jolleys, M., Fu, T.-M., Allan, J. D., Bower, K. N., Capes, G., Crosier, J., Morgan, W. T., Robinson, N. H., Williams, P. I., Cubison, M. J., DeCarlo, P. F., and Dunlea, E. J.: Exploring the vertical profile of atmospheric organic aerosol: comparing 17 aircraft field campaigns with a global model, Atmos. Chem. Phys., 11, 12673-12696, doi:10.5194/acp-11-12673-2011, 2011.

Hearn, J. D. and Smith, G. D.: Kinetics and Product Studies for Ozonolysis Reactions of Organic Particles Using Aerosol CIMS, J. Phys. Chem. A, 108, 10019-10029, doi:10.1021/jp0404145, 2004.

Henry, K. M. and Donahue, N. M.: Photochemical Aging of $\alpha$-Pinene Secondary Organic Aerosol: Effects of $\mathrm{OH}$ Radical Sources and Photolysis, J. Phys. Chem. A, 116, 5932-5940, 2012.

Hess, M., Koepke, P., and Schult, I.: Optical properties of aerosols and clouds: The software package OPAC, B. Am. Meteorol. Soc., 79, 831-844, 1998.

Hodzic, A., Jimenez, J. L., Madronich, S., Canagaratna, M. R., DeCarlo, P. F., Kleinman, L., and Fast, J.: Modeling organic aerosols in a megacity: potential contribution of semi-volatile and intermediate volatility primary organic compounds to secondary or- 
ganic aerosol formation, Atmos. Chem. Phys., 10, 5491-5514, doi:10.5194/acp-10-5491-2010, 2010.

Hodzic, A., Aumont, B., Knote, C., Lee-Taylor, J., Madronich, S., and Tyndall, G.: Volatility dependence of Henry's law constants of condensable organics: Application to estimate depositional loss of secondary organic aerosols, Geophys. Res. Lett., 41, 4795-4804, doi:10.1002/2014GL060649, 2014.

Hodzic, A., Madronich, S., Kasibhatla, P. S., Tyndall, G., Aumont, B., Jimenez, J. L., Lee-Taylor, J., and Orlando, J.: Organic photolysis reactions in tropospheric aerosols: effect on secondary organic aerosol formation and lifetime, Atmos. Chem. Phys., 15, 9253-9269, doi:10.5194/acp-15-9253-2015, 2015.

Iacono, M. J., Delamere, J. S., Mlawer, E. J., Shephard, M. W., Clough, S. A., and Collins, W. D.: Radiative forcing by long-lived greenhouse gases: Calculations with the AER radiative transfer models, J. Geophys. Res.-Atmos., 113, D13103, doi:10.1029/2008jd009944, 2008.

Jathar, S. H., Farina, S. C., Robinson, A. L., and Adams, P. J.: The influence of semi-volatile and reactive primary emissions on the abundance and properties of global organic aerosol, Atmos. Chem. Phys., 11, 7727-7746, doi:10.5194/acp-11-77272011, 2011.

Jathar, S. H., Gordon, T. D., Hennigan, C. J., Pye, H. O. T., Pouliot, G., Adams, P. J., Donahue, N. M., and Robinson, A. L.: Unspeciated organic emissions from combustion sources and their influence on the secondary organic aerosol budget in the United States, P. Natl. Acad. Sci., 111, 10473-10478, 2014.

Jathar, S. H., Cappa, C. D., Wexler, A. S., Seinfeld, J. H., and Kleeman, M. J.: Simulating secondary organic aerosol in a regional air quality model using the statistical oxidation model - Part 1 : Assessing the influence of constrained multi-generational ageing, Atmos. Chem. Phys., 16, 2309-2322, doi:10.5194/acp-162309-2016, 2016.

Jo, D. S., Park, R. J., Kim, M. J., and Spracklen, D. V.: Effects of chemical aging on global secondary organic aerosol using the volatility basis set approach, Atmos. Environ., 81, 230-244, 2013.

Jolleys, M. D., Coe, H., McFiggans, G., Capes, G., Allan, J. D., Crosier, J., Williams, P. I., Allen, G., Bower, K. N., Jimenez, J. L., Russell, L. M., Grutter, M., and Baumgardner, D.: Characterizing the aging of biomass burning organic aerosol by use of mixing ratios: A meta-analysis of four regions, Environ. Sci. Technol., 46, 13093-13102, doi:10.1021/es302386v, 2012.

Jordan, N. S., Hoff, R. M., and Bacmeister, J. T.: Validation of Goddard Earth Observing System - version 5 MERRA planetary boundary layer heights using CALIPSO, J. Geophys. Res., 115, D24218, doi:10.1029/2009JD013777, 2010.

Kim, P. S., Jacob, D. J., Fisher, J. A., Travis, K., Yu, K., Zhu, L., Yantosca, R. M., Sulprizio, M. P., Jimenez, J. L., CampuzanoJost, P., Froyd, K. D., Liao, J., Hair, J. W., Fenn, M. A., Butler, C. F., Wagner, N. L., Gordon, T. D., Welti, A., Wennberg, P. O., Crounse, J. D., St. Clair, J. M., Teng, A. P., Millet, D. B., Schwarz, J. P., Markovic, M. Z., and Perring, A. E.: Sources, seasonality, and trends of southeast US aerosol: an integrated analysis of surface, aircraft, and satellite observations with the GEOS-Chem chemical transport model, Atmos. Chem. Phys., 15, 10411-10433, doi:10.5194/acp-15-10411-2015, 2015.

Knote, C., Hodzic, A., Jimenez, J. L., Volkamer, R., Orlando, J. J., Baidar, S., Brioude, J., Fast, J., Gentner, D. R., Goldstein, A. H.,
Hayes, P. L., Knighton, W. B., Oetjen, H., Setyan, A., Stark, H., Thalman, R., Tyndall, G., Washenfelder, R., Waxman, E., and Zhang, Q.: Simulation of semi-explicit mechanisms of SOA formation from glyoxal in aerosol in a 3-D model, Atmos. Chem. Phys., 14, 6213-6239, doi:10.5194/acp-14-6213-2014, 2014.

Knote, C., Hodzic, A., and Jimenez, J. L.: The effect of dry and wet deposition of condensable vapors on secondary organic aerosols concentrations over the continental US, Atmos. Chem. Phys., 15, 1-18, doi:10.5194/acp-15-1-2015, 2015.

Kroll, J. H., Smith, J. D., Che, D. L., Kessler, S. H., Worsnop, D. R., and Wilson, K. R.: Measurement of fragmentation and functionalization pathways in the heterogeneous oxidation of oxidized organic aerosol, Phys. Chem. Chem. Phys., 11, 8005-8014, 2009.

La, Y. S., Camredon, M., Ziemann, P. J., Valorso, R., Matsunaga, A., Lannuque, V., Lee-Taylor, J., Hodzic, A., Madronich, S., and Aumont, B.: Impact of chamber wall loss of gaseous organic compounds on secondary organic aerosol formation: explicit modeling of SOA formation from alkane and alkene oxidation, Atmos. Chem. Phys., 16, 1417-1431, doi:10.5194/acp-161417-2016, 2016.

Lane, T., Donahue, N., and Pandis, S.: Simulating secondary organic aerosol formation using the volatility basis-set approach in a chemical transport model, Atmos. Environ., 42, 7439-7451, doi:10.1016/j.atmosenv.2008.06.026, 2008.

Lee-Taylor, J., Madronich, S., Aumont, B., Baker, A., Camredon, M., Hodzic, A., Tyndall, G. S., Apel, E., and Zaveri, R. A.: Explicit modeling of organic chemistry and secondary organic aerosol partitioning for Mexico City and its outflow plume, Atmos. Chem. Phys., 11, 13219-13241, doi:10.5194/acp-1113219-2011, 2011.

Lelieveld, J., Evans, J. S., Fnais, M., Giannadaki, D., and Pozzer, A.: The contribution of outdoor air pollution sources to premature mortality on a global scale, Nature, 525, 367-371, doi:10.1038/nature15371, 2015.

Lim, S. S., Vos, T., Flaxman, A. D., Danaei, G., Shibuya, K., Adair-Rohani, H., Amann, M., Anderson, H. R., Andrews, K. G., Aryee, M., Atkinson, C., Bacchus, L. J., Bahalim, A. N., Balakrishnan, K., Balmes, J., Barker-Collo, S., Baxter, A., Bell, M. L., Blore, J. D., Blyth, F., Bonner, C., Borges, G., Bourne, R., Boussinesq, M., Brauer, M., Brooks, P., Bruce, N. G., Brunekreef, B., Bryan-Hancock, C., Bucello, C., Buchbinder, R., Bull, F., Burnett, R. T., Byers, T. E., Calabria, B., Carapetis, J., Carnahan, E., Chafe, Z., Charlson, F., Chen, H., Chen, J. S., Cheng, A. T., Child, J. C., Cohen, A., Colson, K. E., Cowie, B. C., Darby, S., Darling, S., Davis, A., Degenhardt, L., Dentener, F., Des Jarlais, D. C., Devries, K., Dherani, M., Ding, E. L., Dorsey, E. R., Driscoll, T., Edmond, K., Ali, S. E., Engell, R. E., Erwin, P. J., Fahimi, S., Falder, G., Farzadfar, F., Ferrari, A., Finucane, M. M., Flaxman, S., Fowkes, F. G., Freedman, G., Freeman, M. K., Gakidou, E., Ghosh, S., Giovannucci, E., Gmel, G., Graham, K., Grainger, R., Grant, B., Gunnell, D., Gutierrez, H. R., Hall, W., Hoek, H. W., Hogan, A., Hosgood III, H. D., Hoy, D., Hu, H., Hubbell, B. J., Hutchings, S. J., Ibeanusi, S. E., Jacklyn, G. L., Jasrasaria, R., Jonas, J. B., Kan, H., Kanis, J. A., Kassebaum, N., Kawakami, N., Khang, Y. H., Khatibzadeh, S., Khoo, J. P., Kok, C., Laden, F., Lalloo, R., Lan, Q., Lathlean, T., Leasher, J. L., Leigh, J., Li, Y., Lin, J. K., Lipshultz, S. E., London, S., Lozano, R., Lu, Y., Mak, J., Malekzadeh, R., Mallinger, L., Marcenes, W., March, L., Marks, R., Martin, R., McGale, P., 
McGrath, J., Mehta, S., Mensah, G. A., Merriman, T. R., Micha, R., Michaud, C., Mishra, V., Mohd Hanafiah, K., Mokdad, A. A., Morawska, L., Mozaffarian, D., Murphy, T., Naghavi, M., Neal, B., Nelson, P. K., Nolla, J. M., Norman, R., Olives, C., Omer, S. B., Orchard, J., Osborne, R., Ostro, B., Page, A., Pandey, K. D., Parry, C. D., Passmore, E., Patra, J., Pearce, N., Pelizzari, P. M., Petzold, M., Phillips, M. R., Pope, D., Pope III, C. A., Powles, J., Rao, M., Razavi, H., Rehfuess, E. A., Rehm, J. T., Ritz, B., Rivara, F. P., Roberts, T., Robinson, C., Rodriguez-Portales, J. A., Romieu, I., Room, R., Rosenfeld, L. C., Roy, A., Rushton, L., Salomon, J. A., Sampson, U., Sanchez-Riera, L., Sanman, E., Sapkota, A., Seedat, S., Shi, P., Shield, K., Shivakoti, R., Singh, G. M., Sleet, D. A., Smith, E., Smith, K. R., Stapelberg, N. J., Steenland, K., Stöckl, H., Stovner, L. J., Straif, K., Straney, L., Thurston, G. D., Tran, J. H., Van Dingenen, R., van Donkelaar, A., Veerman, J. L., Vijayakumar, L., Weintraub, R., Weissman, M. M., White, R. A., Whiteford, H., Wiersma, S. T., Wilkinson, J. D., Williams, H. C., Williams, W., Wilson, N., Woolf, A. D., Yip, P., Zielinski, J. M., Lopez, A. D., Murray, C. J., Ezzati, M., AlMazroa, M. A., and Memish, Z. A.: A comparative risk assessment of burden of disease and injury attributable to 67 risk factors and risk factor clusters in 21 regions, 1990-2010: a systematic analysis for the Global Burden of Disease Study 2010, Lancet, 380, 2224-2260, 2012 (Erratum, Lancet, 381, p. 628, 2013).

Liu, H., Jacob, D. J., Bey, I., and Yantosca, R. M.: Constraints from ${ }^{210} \mathrm{~Pb}$ and ${ }^{7} \mathrm{Be}$ on wet deposition and transport in a global threedimensional chemical tracer model driven by assimilated meteorological fields, J. Geophys. Res., 106, 12109-12128, 2001.

Madronich, S.: The atmosphere and UV-B radiation at ground level, Environmental UV Photobiology, Plenum Press, Springer US, 139, doi:10.1007/978-1-4899-2406-3_1, 1993.

Matsunaga, A. and Ziemann, P. J.: Gas-Wall Partitioning of Organic Compounds in a Teflon Film Chamber and Potential Effects on Reaction Product and Aerosol Yield Measurements, Aerosol Sci. Tech., 44, 881-892, doi:10.1080/02786826.2010.501044, 2010.

Moise, T. and Rudich, Y.: Reactive uptake of ozone by proxies for organic aerosols: Surface versus bulk processes, J. Geophys. Res., 105, 14667-14676, doi:10.1029/2000JD900071, 2000.

Moise, T. and Rudich, Y.: Reactive uptake of ozone by aerosol associated unsaturated fatty acids: Kinetics, mechanism, and products, J. Phys. Chem. A, 106, 6469-6476, 2002.

Moise, T., Talukdar, R. K., Frost, G. J., Fox, R. W., and Rudich, Y.: Reactive uptake of $\mathrm{NO}_{3}$ by liquid and frozen organics, J. Geophys. Res., 107, 4014, doi:10.1029/2001JD000334, 2002.

Molina, M. J., Ivanov, A. V., Trakhtenberg, S., and Molina, L. T.: Atmospheric evolution of organic aerosol, Geophys. Res. Lett., 31, L22104, doi:10.1029/2004GL020910, 2004.

NASA: SEAC4RS data, available at: http://www-air.larc.nasa.gov, last access: 1 March 2015.

NCAR: Photolysis model TUV, available at: http://cprm.acom.ucar. edu/Models/TUV/Interactive_TUV/, last access: 1 March 2015.

NILU: EMEP data, available at: http://ebas.nilu.no, last access: 1 March 2015.

Odum, J. R., Hoffmann, T., Bowman, F., Collins, D., Flagan, R. C., and Seinfeld, J. H.: Gas/partitioning and secondary organic aerosol yields, Environ. Sci. Technol., 30, 2580-2585, 1996.

Ortega, A. M., Hayes, P. L., Peng, Z., Palm, B. B., Hu, W., Day, D. A., Li, R., Cubison, M. J., Brune, W. H., Graus, M., Warneke, C., Gilman, J. B., Kuster, W. C., de Gouw, J. A., and Jimenez, J. L.:
Real-time measurements of secondary organic aerosol formation and aging from ambient air in an oxidation flow reactor in the Los Angeles area, Atmos. Chem. Phys. Discuss., 15, 21907-21958, doi:10.5194/acpd-15-21907-2015, 2015.

Pye, H. O. T. and Seinfeld, J. H.: A global perspective on aerosol from low-volatility organic compounds, Atmos. Chem. Phys., 10, 4377-4401, doi:10.5194/acp-10-4377-2010, 2010.

Paulot, F., Crounse, J. D., Kjaergaard, H. G., Kuerten, A., St. Clair, J. M., Seinfeld, J. H., and Wennberg, P. O.: Unexpected Epoxide Formation in the Gas-Phase Photooxidation of Isoprene, Science, 325, 730-733, 2009.

Rienecker, M. M., Suarez, M. J., Gelaro, R., Todling, R., Bacmeister, J., Liu, E., Bosilovich, M. G., Schubert, S. D., Takacs, L., and Kim, G.-K.: MERRA: NASA's modern-era retrospective analysis for research and applications, J. Climate, 24, 3624-3648, 2011.

Robinson, A. L., Donahue, N. M., Shrivastava, M., Weitkamp, E. A., Sage, A. M., Grieshop, A. P., Lane, T. E., Pierce, J. R., and Pandis, S. N.: Rethinking organic aerosols: Semivolatile emissions and photochemical aging, Science, 315, 1259-1262, doi:10.1126/science.1133061, 2007.

SEDAC: Gridded population data for 2005, available at: http:// sedac.ciesin.columbia.edu, last access: 1 March 2015.

Seinfeld, J. H. and Pandis, S. N.: Atmospheric Chemistry and Physics: From Air Pollution to Climate Change, 2nd Edn., John Wiley and Sons, Hoboken, New Jersey, 2006.

Shiraiwa, M., Yee, L. D., Schilling, K. A., Loza, C. L., Craven, J. S., Zuend, A., Ziemann, P. J., and Seinfeld, J. H.: Size distribution dynamics reveal particle-phase chemistry in organic aerosol formation, P. Natl. Acad. Sci. USA, 11029, 11746-11750, 2013.

Shrivastava, M., Fast, J., Easter, R., Gustafson Jr., W. I., Zaveri, R. A., Jimenez, J. L., Saide, P., and Hodzic, A.: Modeling organic aerosols in a megacity: comparison of simple and complex representations of the volatility basis set approach, Atmos. Chem. Phys., 11, 6639-6662, doi:10.5194/acp-11-6639-2011, 2011.

Shrivastava, M., Easter, R. C., Liu, X., Zelenyuk, A., Singh, B., Zhang, K., Ma, P.-L., Chand, D., Ghan, S., Jimenez, J. L., Zhang, Q., Fast, J., Rasch, P. J., and Tiitta, P.: Global transformation and fate of SOA: Implications of low-volatility SOA and gas-phase fragmentation reactions, J. Geophys. Res.-Atmos., 120, 41694195, doi:10.1002/2014JD022563, 2015.

Simpson, D., Yttri, K. E., Klimont, Z., Kupiainen, K., Caseiro, A., Gelencsér, C., Pio, H., Puxbaum, H., and Legrand, M.: Modeling carbonaceous aerosol over Europe: Analysis of the CARBOSOL and EMEP EC/OC campaigns, J. Geophys. Res., 112, D23S14, doi:10.1029/2006JD008158, 2007.

Spracklen, D. V., Jimenez, J. L., Carslaw, K. S., Worsnop, D. R., Evans, M. J., Mann, G. W., Zhang, Q., Canagaratna, M. R., Allan, J., Coe, H., McFiggans, G., Rap, A., and Forster, P.: Aerosol mass spectrometer constraint on the global secondary organic aerosol budget, Atmos. Chem. Phys., 11, 12109-12136, doi:10.5194/acp-11-12109-2011, 2011.

St. Clair, J. M., Rivera-Rios, J. C., Crounse, J. D., Knap, H. C., Bates, K. H., Teng, A. P., Jørgensen, S., Kjaergaard, H. G., Keutsch, F. N., and Wennberg, P. O.: Kinetics and Products of the Reaction of the First-Generation Isoprene Hydroxy Hydroperoxide (ISOPOOH) with OH, J. Phys. Chem. A, 120, 1441-1451, doi:10.1021/acs.jpca.5b06532, 2015.

Surratt, J. D., Chan, A. W. H., Eddingsaas, N. C., Chan, M., Loza, C. L., Kwan, A. J., Hersey, S. P., Flagan, R. C., Wennberg, P. O., 
and Seinfeld, J. H.: Reactive intermediates revealed in secondary organic aerosol formation from isoprene, P. Natl. Acad. Sci., 107, 6640-6645, doi:10.1073/pnas.0911114107, 2010.

Tsigaridis, K., Daskalakis, N., Kanakidou, M., Adams, P. J., Artaxo, P., Bahadur, R., Balkanski, Y., Bauer, S. E., Bellouin, N., Benedetti, A., Bergman, T., Berntsen, T. K., Beukes, J. P., Bian, H., Carslaw, K. S., Chin, M., Curci, G., Diehl, T., Easter, R. C., Ghan, S. J., Gong, S. L., Hodzic, A., Hoyle, C. R., Iversen, T., Jathar, S., Jimenez, J. L., Kaiser, J. W., Kirkevåg, A., Koch, D., Kokkola, H., Lee, Y. H., Lin, G., Liu, X., Luo, G., Ma, X., Mann, G. W., Mihalopoulos, N., Morcrette, J.-J., Müller, J.-F., Myhre, G., Myriokefalitakis, S., Ng, N. L., O’Donnell, D., Penner, J. E., Pozzoli, L., Pringle, K. J., Russell, L. M., Schulz, M., Sciare, J., Seland, Ø., Shindell, D. T., Sillman, S., Skeie, R. B., Spracklen, D., Stavrakou, T., Steenrod, S. D., Takemura, T., Tiitta, P., Tilmes, S., Tost, H., van Noije, T., van Zyl, P. G., von Salzen, K., Yu, F., Wang, Z., Wang, Z., Zaveri, R. A., Zhang, H., Zhang, K., Zhang, Q., and Zhang, X.: The AeroCom evaluation and intercomparison of organic aerosol in global models, Atmos. Chem. Phys., 14, 10845-10895, doi:10.5194/acp-1410845-2014, 2014.

Tsimpidi, A. P., Karydis, V. A., Zavala, M., Lei, W., Molina, L., Ulbrich, I. M., Jimenez, J. L., and Pandis, S. N.: Evaluation of the volatility basis-set approach for the simulation of organic aerosol formation in the Mexico City metropolitan area, Atmos. Chem. Phys., 10, 525-546, doi:10.5194/acp-10-525-2010, 2010.

Wesely, M. L.: Parameterizations of surface resistance to gaseous dry deposition in regional-scale, numerical models, Atmos. Environ., 23, 1293-1304, 1989.

Wiscombe, W. J.: Improved Mie scattering algorithms, Appl. Optics, 19, 1505-1509, 1980.
Wong, J. P. S., Zhou, S., and Abbatt, P. D.: Changes in Secondary Organic Aerosol Composition and Mass due to Photolysis: Relative Humidity Dependence, J. Phys. Chem. A, 119, 4309-4316, doi:10.1021/jp506898c, 2014.

Yttri, K. E., Aas, W., Bjerke, A., Cape, J. N., Cavalli, F., Ceburnis, D., Dye, C., Emblico, L., Facchini, M. C., Forster, C., Hanssen, J. E., Hansson, H. C., Jennings, S. G., Maenhaut, W., Putaud, J. P., and Tørseth, K.: Elemental and organic carbon in $\mathrm{PM}_{10}$ : a one year measurement campaign within the European Monitoring and Evaluation Programme EMEP, Atmos. Chem. Phys., 7, 5711-5725, doi:10.5194/acp-7-5711-2007, 2007.

Zhang, Q., Jimenez, J. L., Canagaratna, M. R., Allan, J. D., Coe, H., Ulbrich, I., Alfarra, M. R., Takami, A., Middlebrook, A M., Sun, Y. L., Dzepina, K., Dunlea, E., Docherty, K., DeCarlo, P. F., Salcedo, D., Onasch, T., Jayne, J. T., Miyoshi, T., Shimono, A., Hatakeyama, S., Takegawa, N., Kondo, Y., Schneider, J., Drewnick, F., Borrmann, S., Weimer, S., Demerjian, K., Williams, P., Bower, K., Bahreini, R., Cottrell, L., Griffin, R. J., Rautiainen, J., Sun, J. Y., Zhang, Y. M., and Worsnop, D. R.: Ubiquity and dominance of oxygenated species in organic aerosols in anthropogenically-influenced Northern Hemisphere midlatitudes, Geophys. Res. Lett., 34, L13801, doi:10.1029/2007g1029979, 2007.

Zhang, X., Cappa, C. D., Jathar, S. H., McVay, R. C., Ensberg, J. J., Kleeman, M. J., and Seinfeld, J. H.: Influence of vapor wall loss in laboratory chambers on yields of secondary organic aerosol, $\mathrm{P}$. Natl. Acad. Sci. USA, 111, 5802-5807, 2014. 